Económica, La Plata, Vol. LXIV, Nro. 1, 2019

\title{
EXPLORANDO LOS CAMBIOS DE LA POBREZA EN ARGENTINA: 2003-2015
}

\section{JESSICA BRACCO, LEONARDO GASPARINI Y LEOPOLDO TORNAROLLI}

\begin{abstract}
This paper explores the changes in income poverty in Argentina during the period 2003-2015 using various decomposition methodologies. The results suggest that the generalized improvement in the labor market after the crisis was the main factor behind the sharp fall in poverty in the period 2003-2007. In contrast, the reduction of poverty between 2007 and 2011 is associated with the most active role played by social policy. Finally, during the period 2011-2015, no factor could contribute significantly to the reduction of poverty.
\end{abstract}

JEL classification: C15; D31; D33; I32; J31.

Keywords: poverty, inequality, income, Argentina.

\section{RESUMEN}

Este trabajo explora los cambios en la pobreza de ingresos en Argentina durante el período 2003-2015 utilizando diversas metodologías de descomposición. Los resultados sugieren que la mejora generalizada en el mercado laboral luego de la crisis fue el principal factor detrás de la fuerte caída de la pobreza en el período 2003-2007. En contraste, la reducción de la pobreza durante la etapa 2007-2011 está asociada al papel más activo que tomó la política social. Finalmente, durante el período 2011-2015 ningún factor contribuyó significativamente a la reducción de la pobreza.

Clasificación JEL: C15; D31; D33; I32; J31.

Palabras clave: pobreza, desigualdad, ingresos, Argentina.

Recibido: 17/09/2019. Aceptado: 26/12/2019

DOI: https://doi.org/10.24215/18521649e009 


\title{
EXPLORANDO LOS CAMBIOS DE LA POBREZA EN ARGENTINA: 2003-2015 ${ }^{1}$
}

\author{
JESSICA BRACCO, LEONARDO GASPARINI Y LEOPOLDO \\ TORNAROLLI ${ }^{2}$
}

\section{Introducción}

En las últimas décadas Argentina ha experimentado cambios marcados en sus niveles de pobreza monetaria. Conocer las razones de esa dinámica es de enorme relevancia, tanto desde un punto de vista académico, como para la política pública. Sin embargo, por problemas típicos de las ciencias sociales este objetivo resulta difícil de alcanzar: son muchas las dificultades metodológicas que impiden identificar con precisión los factores causales profundos de los cambios en la pobreza. En su lugar, la Economía busca aportar evidencia empírica parcial que, leída en su conjunto y acompañada de teoría, puede contribuir a entender la dinámica de fenómenos agregados complejos, como es el de la evolución de la pobreza.

Este trabajo se suma a los esfuerzos por entender los cambios sociales experimentados por Argentina en los últimos años, específicamente durante el período 2003-2015. Este es no sólo un período que coincide con una etapa política particular en el país, sino que abarca años sin cambios significativos en la principal fuente de información para las estimaciones de pobreza: la Encuesta Permanente de Hogares (EPH). Aspectos importantes de esta encuesta fueron modificados sustancialmente tanto en 2003 (el cuestionario y el período de implementación) como en 2016 (la estructura de ponderadores, el tratamiento de la no respuesta de ingresos, etc.), por lo que la comparabilidad de los resultados se debilita fuera de la ventana temporal analizada en este trabajo.

\footnotetext{
${ }^{1}$ Los autores agradecen los comentarios y sugerencias de Javier Alejo, Mariana Marchionni y Pablo Gluzmann, de los participantes de seminarios en la UNLP y AAEP, y de dos revisores anónimos. Los eventuales errores son de nuestra exclusiva responsabilidad.

${ }^{2}$ Centro de Estudios Distributivos Laborales y Sociales (CEDLAS) - Instituto de Investigaciones Económicas, Facultad de Ciencias Económicas, Universidad Nacional de La Plata. Leonardo Gasparini es también investigador del CONICET.
} 
Los años del período 2003-2015 se dividen en este estudio en tres etapas, que se corresponden con dinámicas diferentes de la pobreza y de otras variables sociales y económicas: expansión económica y caída fuerte de la pobreza entre 2003 y 2007, desaceleración económica y descenso moderado de la pobreza entre 2007 y 2011, y estancamiento económico y de las mejoras sociales entre 2011 y 2015 . El trabajo caracteriza la dinámica de la pobreza y algunos de sus factores asociados en cada uno de estos subperíodos.

El aporte de este estudio consiste en aplicar un conjunto de descomposiciones basadas en microsimulaciones con el objeto de caracterizar los cambios recientes de la pobreza de ingresos en cada una de las tres etapas del período 2003-2015. En particular, se aplican variantes de las descomposiciones de Datt y Ravallion (1992), Bourguignon, Ferreira y Lustig (2005) y Azevedo, Nguyen y Sanfelice (2012) ${ }^{3}$. Más allá de sus diferencias, estas descomposiciones tienen una lógica común: permiten estimar el cambio en la pobreza o la desigualdad como resultado del cambio de algún factor, manteniendo constante el resto. Este tipo de ejercicio tiene algunos problemas extensamente discutidos en la literatura. En particular, las descomposiciones sólo proveen estimaciones del efecto directo -de equilibrio parcial- del cambio en un factor sobre el fenómeno bajo estudio, por lo que sufren de inconsistencia en el equilibrio: se basan en simulaciones de la distribución del ingreso que no reflejan un equilibrio económico general. Representan más bien un ejercicio estadístico, en el que se asume que es posible modificar un cierto determinante, por ejemplo, los salarios, y mantener todo lo demás constante. De todos modos, y a pesar de que estas metodologías no permiten una interpretación causal, representan una herramienta útil para caracterizar cambios en indicadores sociales y dar órdenes de magnitud inicial del impacto de varios de sus determinantes. Por ello, las descomposiciones ocupan un lugar central en el instrumental económico usado para estudiar fenómenos sociales, como la pobreza o la desigualdad (Fortin, Lemieux y Firpo, 2011).

Existe una nutrida literatura que utiliza diversas descomposiciones para

\footnotetext{
${ }^{3}$ La literatura de descomposiciones es extensa y variada. Algunas alternativas y extensiones a las metodologías utilizadas en este trabajo incluyen descomposiciones agregadas (Tsakloglou, 1993); microdescomposiciones lineales (Jhun et al. 1993); descomposiciones por cuantiles (Machado y Mata, 2005), descomposiciones no paramétricas (Dinardo et al., 1996) y descomposiciones RIF (Firpo et al., 2009). Ver Fortin et al. (2011) para una discusión de características, ventajas y desventajas de estas metodologías.
} 
analizar la dinámica de la pobreza y la desigualdad en Argentina. Ejemplos de esta literatura son Altimir et al. (2002); Gasparini et al. (2005); Bustelo y Lucchetti (2004); Marchionni y Gasparini (2007); Gasparini y Cruces (2009); Bertranou y Maurizio (2011); Zoloa (2011); Beccaria, Maurizio y Vázquez (2014) y César (2016). Inchauste, et al. (2014) y Azevedo et al. (2013) incluyen resultados para Argentina dentro de un análisis más general para América Latina. Este trabajo realiza dos contribuciones principales en el marco de esta literatura. En primer lugar, brinda resultados sobre un período reciente -2003-2015- sobre el que existe evidencia todavía escasa. El período elegido es particularmente interesante ya que si bien es homogéneo en términos del color político de la administración nacional, abarca etapas muy distintas en relación a la dinámica de la pobreza. En segundo lugar, el trabajo propone un sendero de análisis en base a tres descomposiciones distintas que van gradualmente añadiendo información para una caracterización más detallada de la dinámica de la pobreza en el período.

El resto del trabajo se estructura de la siguiente forma. En la sección 2 se describen los datos utilizados y se presenta y discute el fenómeno central a tratar: la evolución de la pobreza de ingresos en Argentina en el período 2003-2015. La medición de la pobreza no ha sido un ejercicio lineal en el caso argentino, caracterizado por cambios de metodologías y problemas de confiabilidad. En dicha sección se resumen estas discusiones y se propone una serie de pobreza que se analiza en el resto del trabajo.

Los cambios en la pobreza monetaria en un determinado período son resultado de cuánto y cómo se mueven los ingresos en ese período. $\mathrm{O}$, más técnicamente, la evolución de la pobreza se puede explicar por la interacción entre los cambios en la posición y las modificaciones en la forma de la distribución del ingreso. En la sección 3 se intenta aislar estadísticamente esos dos aspectos a partir de un primer ejercicio de descomposiciones. Más concretamente, el ejercicio expresa el cambio observado en la pobreza en dos componentes: uno proveniente del crecimiento económico neutral (cuánto) y otro que es consecuencia únicamente de cambios en la desigualdad en la distribución del ingreso (cómo). Con este objetivo en este trabajo se sigue una variante de la propuesta de Datt y Ravallion (1992).

En la realidad, los cambios en el crecimiento y la desigualdad ocurren en forma conjunta y obedecen a factores que se modifican en simultáneo e 
interactúan entre ellos. Por ejemplo, la tasa de crecimiento del ingreso total depende de las tasas de crecimiento de las distintas fuentes de ingreso y de la participación relativa de esas fuentes en el ingreso total. Pero dado que la composición por fuentes de los ingresos de los hogares ubicados en distintos puntos de la distribución difiere, tasas de crecimiento diferentes entre fuentes de ingreso afectarán la desigualdad en la distribución del ingreso. La sección 4 ahonda en el análisis de esas interacciones. Inicialmente se estudia cómo se compuso el crecimiento del ingreso de los hogares de los distintos deciles en cada una de las etapas analizadas. Luego se aplica una descomposición, propuesta por Azevedo et al. (2012), para evaluar la relevancia relativa de cambios en las distintas fuentes de ingreso sobre la desigualdad total. Posteriormente se analizan por separado los ingresos laborales, los no laborales y algunos factores demográficos. Para el análisis de los ingresos laborales y de los factores demográficos se aplica una variante de la metodología propuesta por Bourguignon et al. (2005), adaptada para el caso argentino por Gasparini, Marchionni y Sosa Escudero (2005), que permite medir la relevancia de varios factores que podrían haber influido en el cambio de la desigualdad de ingresos. En particular, esta metodología permite separar los efectos provenientes de cambios en las dotaciones de la población (como cambios en la estructura educativa o poblacional), cambios generados en los retornos a aquellas dotaciones (como la retribución a la educación) y cambios en factores no observables (como la habilidad). El análisis de los ingresos no laborales es descriptivo, pero permite apreciar con claridad los factores que explican la contribución de dichos ingresos en la evolución de la desigualdad en el período bajo análisis.

Por último, se cierra el trabajo en la sección 5 con una evaluación global de los resultados de las secciones anteriores.

\section{La dinámica de la pobreza}

La medición de la pobreza es un ejercicio que requiere adoptar convenciones tanto conceptuales como metodológicas (Sen, 1976; Deaton, 1997). En este trabajo seguimos el enfoque de la pobreza monetaria: es pobre quien tiene un ingreso familiar por debajo de un umbral, llamado línea de pobreza. Desde la década de 1980 Argentina mide oficialmente la pobreza monetaria 
combinando datos de ingreso familiar por adulto equivalente de la EPH con líneas de indigencia basadas en una canasta de alimentos cuyo valor se actualiza mensualmente, y líneas de pobreza construidas con el método de Orshansky. Si bien el procedimiento es sencillo, a lo largo de los últimos años ha habido cambios metodológicos e interferencias en el cálculo tradicional, lo que ha generado confusiones y debates. La siguiente sub-sección presenta la metodología seguida en este trabajo para construir una serie comparable de pobreza de ingresos en Argentina, mientras que la sub-sección 2.2 discute la evolución en el tiempo de las tasas de indigencia y pobreza, que serán el objeto de análisis en el resto del documento.

\section{II.1 Datos y metodología}

Los datos que se utilizan provienen de la EPH, llevada a cabo por el Instituto Nacional de Estadística y Censos (INDEC). Esta encuesta de hogares, la más representativa del país, se realiza en todos los aglomerados urbanos de más de 100 mil habitantes. Actualmente cubre 31 áreas urbanas en las que habita alrededor del $70 \%$ de la población urbana de Argentina. Dado que el porcentaje de esta población en el país es del $87 \%$, la muestra de la EPH representa cerca del $60 \%$ de la población argentina. Es realizada a lo largo de todo el año, publicada por trimestres y se la conoce como EPH Continua (hasta 2003 se realizaba dos veces al año, en forma puntual).

Las bases de datos de la EPH dejaron de publicarse temporalmente luego del primer semestre de 2015, por los conocidos problemas en los que se encontraba sumido el INDEC desde 2007 y que ya habían llevado al cese de las estimaciones de pobreza e indigencia a partir de 2014. El organismo recién retomó la publicación de la encuesta, y de las estimaciones de indigencia y pobreza, durante el segundo trimestre de 2016. Sin embargo, tanto las nuevas bases de datos como la metodología de estimación de pobreza e indigencia, contienen modificaciones que hacen que no sean comparables en forma directa con las bases de datos y las estimaciones publicadas entre 2003 y 2015 (2013 para el caso de las estimaciones de pobreza e indigencia). En consecuencia, en este trabajo se toma como período de análisis el transcurrido entre el segundo semestre de 2003 y el primer semestre de 2015. Además de ser un período de consistencia metodológica en nuestra principal fuente de datos, estos años 
coinciden con un período político bien definido, comenzado también en 2003 y finalizado en 2015.

Si bien se utilizan las bases de datos del período 2003-2015, la metodología de estimación de la pobreza y la desigualdad que se empleará será la que definió el INDEC en 2016, de modo de poder comparar los valores de pobreza e indigencia que se obtengan con los que se publican desde 2016 y forman parte del debate de políticas públicas actual. Para permitir esa comparabilidad, se aplicó al período 2003-2015 la metodología de estimación propuesta por Tornarolli (2018), la que permite producir resultados para el período analizado que son comparables, con ciertas limitaciones detalladas en el trabajo mencionado, con los resultados de pobreza e indigencia que INDEC publica periódicamente desde septiembre de 2016.

\section{II.2 La evolución de la pobreza}

Las Figuras 1 y 2 resumen la evolución de la pobreza y la indigencia en Argentina durante el período bajo estudio. La tasa de pobreza se redujo desde un valor de 58.2 en 2003 hasta 30.1 en $2015^{4}$. La tasa de indigencia también cayó considerablemente, desde 21.1 en 2003 a 5.9 en 2015. Tanto la dinámica de la pobreza y la indigencia, como la de todos los indicadores económicos de la Argentina, fueron variando marcadamente a lo largo del período analizado, por lo que en lugar de analizar la evolución entre puntas, es conveniente dividir los doce años considerados en tres etapas de cuatro años de duración cada una. La división es, naturalmente, arbitraria, pero resulta ilustrativa.

La primera etapa abarca desde 2003 a 2007 y está marcada por la fuerte expansión económica que se produjo a la salida de la profunda crisis macroeconómica de 2001/02, con salarios reales inicialmente deprimidos luego de la devaluación y en un contexto internacional muy favorable. En ese escenario, el PIB creció a una tasa promedio de $8.5 \%$ anual, un ritmo de crecimiento inédito para el país ${ }^{5}$. Todos los indicadores sociales experimentaron fuertes mejoras en ese período de rebote económico. La tasa de pobreza se redujo desde 58.2 en 2003 a 37.6 en 2007. Tanto la brecha de la pobreza -FGT(1)como la intensidad de la pobreza -FGT(2)- experimentaron también marcados

\footnotetext{
${ }^{4}$ Estas tasas reflejan el porcentaje de personas (no hogares) debajo de la línea de pobreza.

${ }^{5}$ Los datos de crecimiento del PIB provienen de INDEC (2016).
} 
Figura 1: Tasa de pobreza en Argentina, 2003-2015.

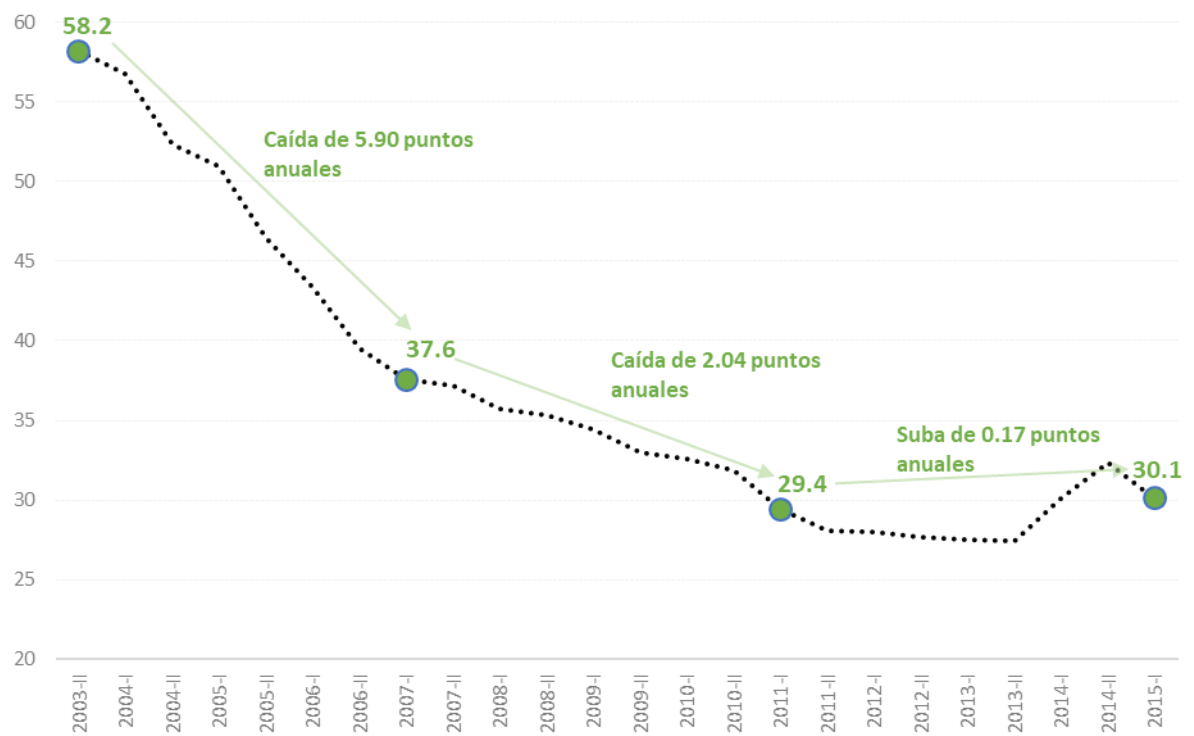

Nota: elaboración propia sobre la base de datos de la EPH y metodología de Tornarolli (2018). 
descensos (Tabla 1). La tasa de indigencia mostró una evolución similar a la de pobreza en el lapso de esos cuatro años de recuperación económica, cayendo de 21.1 a 9.0 .

Figura 2: Tasa de indigencia en Argentina, 2003-2015.

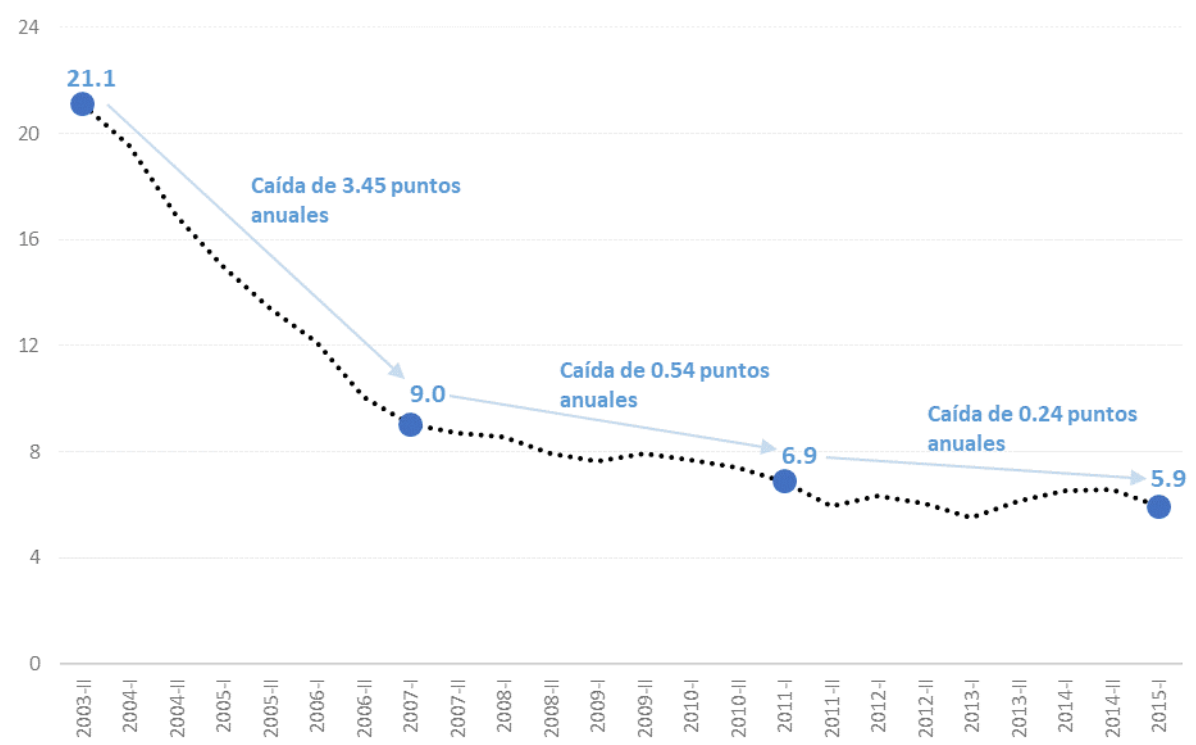

Nota: elaboración propia sobre la base de datos de la EPH y metodología de Tornarolli (2018).

La segunda etapa, que cubre el período 2007-2011, tuvo una dinámica diferente. Con el efecto rebote post-crisis agotado y con condiciones externas buenas pero no extraordinarias, la economía argentina continuó creciendo, pero a tasas menores y con oscilaciones más fuertes. En promedio el PIB aumentó al $3.5 \%$ anual durante esta etapa; una tasa saludable, pero muy inferior a la de la etapa previa. En este contexto, la pobreza de ingresos continuó bajando, aunque a un ritmo menor al del período anterior. Mientras que entre 2003 y 2007 la tasa de pobreza cayó casi 6 puntos por año, en los cuatro años siguientes lo hizo a un ritmo de 2 puntos anuales. La evolución del resto de los indicadores de pobreza e indigencia también marca la desaceleración en las mejoras sociales. 
Tabla 1: Indigencia y pobreza en Argentina

\begin{tabular}{|c|c|c|c|c|c|c|}
\hline & \multicolumn{3}{|c|}{ Tasa de Indigencia } & \multicolumn{3}{|c|}{ Tasa de Pobreza } \\
\hline & FGT (0) & FGT (1) & FGT (2) & FGT (0) & FGT (1) & FGT (2) \\
\hline 2003-II & 21.1 & 9.8 & 6.2 & 58.2 & 29.5 & 19.1 \\
\hline I-2004 & 19.5 & 9.1 & 6.0 & 56.8 & 28.4 & 18.2 \\
\hline 2004-II & 16.9 & 7.0 & 4.2 & 52.3 & 24.7 & 15.3 \\
\hline 2005-I & 15.0 & 6.3 & 3.7 & 50.9 & 23.4 & 14.2 \\
\hline $2005-11$ & 13.4 & 5.3 & 3.1 & 46.5 & 20.8 & 12.4 \\
\hline 2006-I & 12.1 & 5.0 & 2.9 & 43.4 & 19.0 & 11.4 \\
\hline $2006-I I$ & 10.1 & 4.0 & 2.4 & 39.5 & 16.3 & 9.5 \\
\hline 2007-I & 9.0 & 3.4 & 2.0 & 37.6 & 15.3 & 8.8 \\
\hline $2007-11$ & 8.7 & 3.5 & 2.2 & 37.2 & 15.1 & 8.7 \\
\hline 2008-I & 8.6 & 3.3 & 2.0 & 35.7 & 14.5 & 8.3 \\
\hline 2008-II & 7.9 & 3.0 & 1.8 & 35.4 & 14.2 & 8.0 \\
\hline 2009-I & 7.6 & 3.1 & 2.0 & 34.4 & 13.8 & 7.9 \\
\hline $2009-11$ & 7.9 & 3.1 & 1.9 & 33.0 & 13.4 & 7.8 \\
\hline I-2010 & 7.7 & 2.8 & 1.7 & 32.6 & 12.5 & 6.9 \\
\hline $2010-I I$ & 7.4 & 2.6 & 1.5 & 31.9 & 12.1 & 6.6 \\
\hline |-2011 & 6.9 & 2.6 & 1.5 & 29.4 & 10.9 & 5.9 \\
\hline 2011-II & 5.9 & 2.2 & 1.3 & 28.0 & 9.9 & 5.2 \\
\hline | I & 6.4 & 2.4 & 1.5 & 28.0 & 10.2 & 5.5 \\
\hline 2012-II & 6.1 & 2.3 & 1.3 & 27.6 & 9.8 & 5.2 \\
\hline |-2013 & 5.5 & 2.1 & 1.2 & 27.5 & 9.7 & 5.0 \\
\hline 2013-II & 6.2 & 2.3 & 1.5 & 27.4 & 9.7 & 5.2 \\
\hline I-2014 & 6.5 & 2.6 & 1.6 & 30.1 & 10.8 & 5.8 \\
\hline 2014-II & 6.6 & 2.6 & 1.5 & 32.4 & 11.5 & 6.1 \\
\hline |-2015 & 5.9 & 2.1 & 1.3 & 30.1 & 10.4 & 5.3 \\
\hline
\end{tabular}

Nota: elaboración propia sobre la base de datos de la EPH y metodología de Tornarolli (2018). 
La tercera y última etapa, que abarca los años de 2011 a 2015, es un período caracterizado por el estancamiento económico y social. Los desbalances acumulados en años anteriores, las inconsistencias macroeconómicas y un contexto internacional no tan favorable se conjugaron para frenar la economía argentina: el PIB creció a sólo $0.2 \%$ por año, menos que la población, por lo que el producto per cápita se redujo. En ese contexto las mejoras sociales se estancaron: la tasa de pobreza aumentó ligeramente, mientras que otros indicadores de pobreza e indigencia se redujeron solo marginalmente.

En síntesis, la economía argentina experimentó tres etapas claramente diferenciadas entre 2003 y 2015 que tuvieron su correlato en el ritmo de las mejoras sociales: expansión entre 2003 y 2007, desaceleración entre 2007 y 2011 y estancamiento posterior. La próxima sección ahonda en esta vinculación a partir de un ejercicio de descomposiciones.

\section{Crecimiento y distribución}

Los cambios en la pobreza de ingresos están vinculados al crecimiento del ingreso y a los cambios en la desigualdad en la distribución del mismo. El concepto de pobreza absoluta alude a la "masa" en la distribución del ingreso debajo de un umbral fijo en términos reales (la línea de la pobreza), por lo que tanto un aumento proporcional generalizado del ingreso -crecimiento- como un cambio igualador en su distribución contribuyen a reducir la pobreza.

La Figura 3, tomada de Gasparini, Cicowiez y Sosa Escudero (2013), ilustra este punto. Si la distribución del ingreso se traslada de $f(x)$ a $g(x)$, la pobreza -la masa debajo de la línea $z$-cae. Es posible dividir artificialmente el paso desde $f$ a $g$ en dos etapas. La primera asume un aumento proporcional de todos los ingresos y, por ende, un desplazamiento horizontal de la distribución desde $f$ a $f^{*}$. Esta última es una distribución contrafáctica: es semejante a $f$, pero con el ingreso medio de $g$. El paso de $f$ a $f^{*}$ es el "efecto crecimiento". Su impacto sobre la tasa de pobreza es el área $A$. El segundo paso de la descomposición (entre $f^{*}$ y $g$ ) capta el impacto del cambio en la forma de la distribución con media inalterada, que en el caso graficado contribuye también a la caída de la pobreza (área $B$ ). Este cambio es usualmente denominado "efecto redistribución"

\footnotetext{
${ }^{6}$ Nótese que el resultado del ejercicio depende del orden en el que se practica la descomposición. Una alternativa a la explicada consiste en pasar inicialmente de $f$ a una distribución contrafáctica
} 
una explicación más detallada sobre la implementación de esta metodología ver el Apéndice.

Figura 3: Descomposición del cambio en la pobreza.

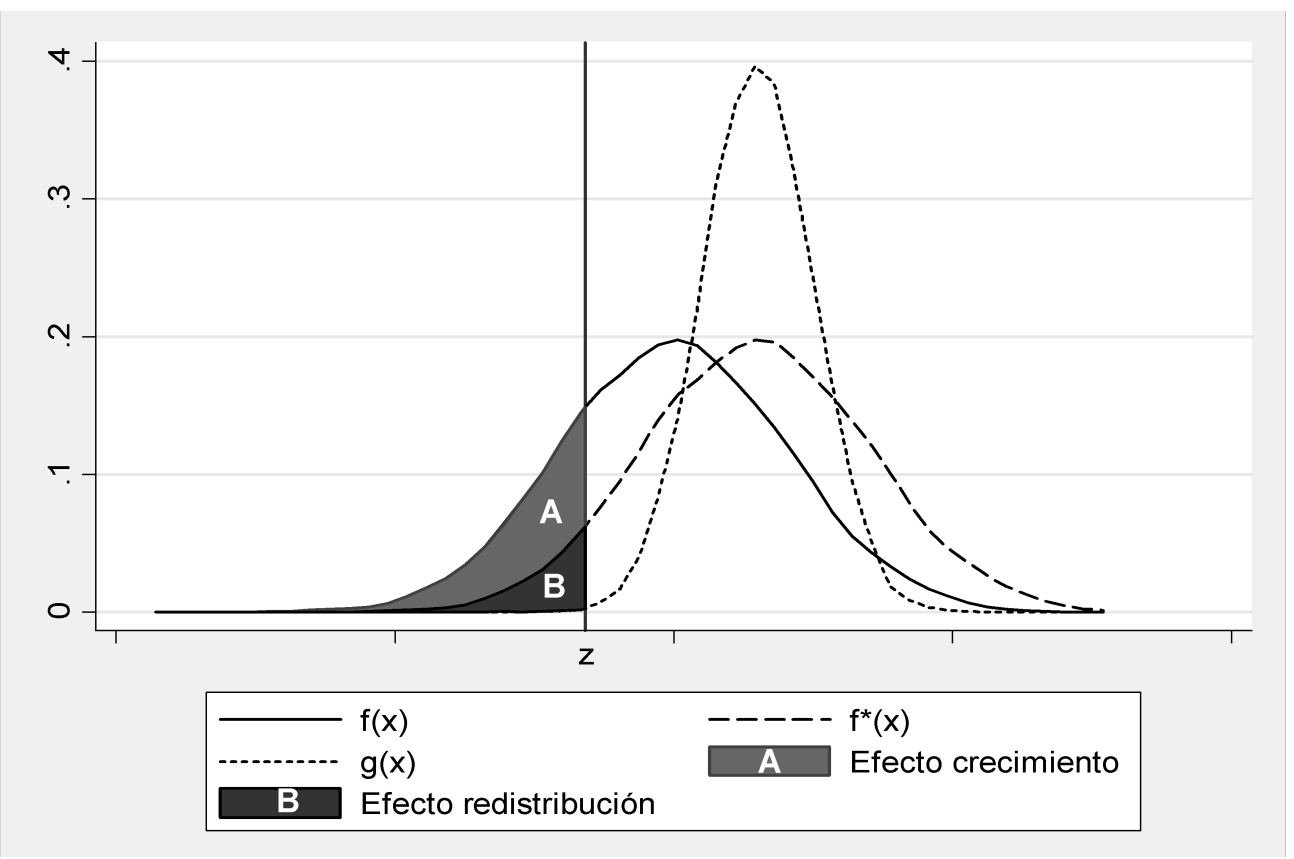

Fuente: Gasparini et al. (2013).

Es importante remarcar que el estudio de la relación mecánica del triángulo pobreza-crecimiento-desigualdad es solo ilustrativo de la dinámica distributiva de una economía, por lo que se requieren esfuerzos adicionales para desentrañar cuáles son las razones profundas del cambio en estas variables en un período.

\section{III.1 Crecimiento y desigualdad entre 2003 y 2015}

con la forma de $g$, pero manteniendo la media en su valor de $f$ (efecto redistribución) y luego pasar de esta distribución a $g$ (efecto crecimiento). Por esto mismo, los resultados que se muestran en el trabajo representan el promedio de estas alternativas (ver Apéndice). 
La descomposición propuesta divide al cambio en la pobreza en dos etapas: el asociado al crecimiento neutral y el vinculado a modificaciones en la desigualdad. La Figura 4 presenta el comportamiento de ambas variables durante el período 2003-2015. En particular, se presenta la evolución del coeficiente de Gini, el indicador más difundido de desigualdad, y de la media del ingreso por adulto equivalente (la variable utilizada para medir pobreza oficial en Argentina) $)^{7}$. Este ingreso medio, calculado a partir de microdatos de la EPH, es dividido por el valor de la línea de pobreza, de manera de captar cambios en términos reales.

Figura 4: Desigualdad y crecimiento en Argentina, 2003-2015. Coeficiente de Gini e ingreso equivalente medio.

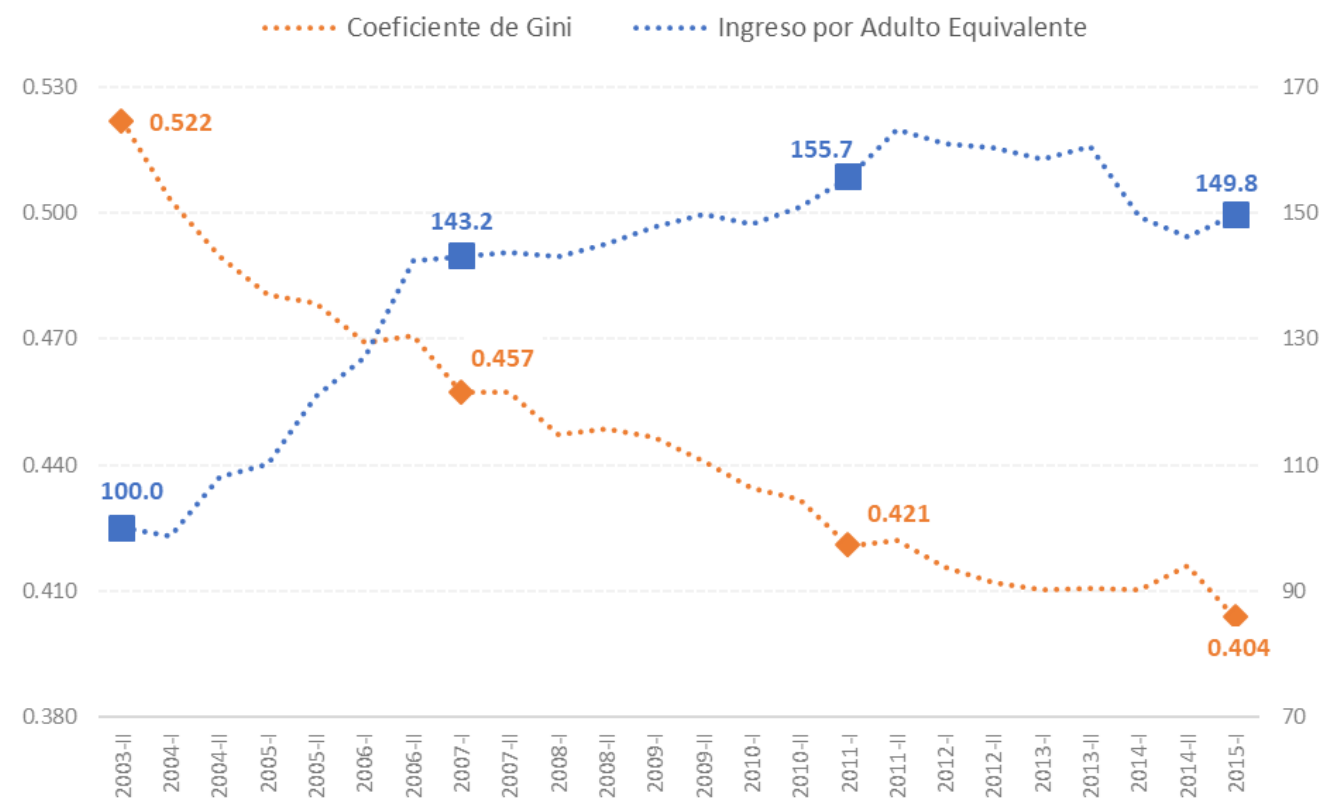

Nota: elaboración propia sobre la base de datos de la EPH.

La dinámica de la desigualdad y el ingreso medio puede dividirse en las tres

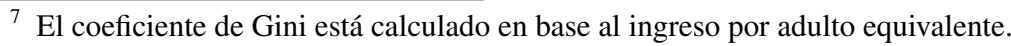


etapas propuestas en la sección anterior. En coincidencia con la evolución del PIB, el ingreso disponible por adulto equivalente captado en la EPH creció a una tasa muy alta durante el período de rebote económico 2003-2007: $9.4 \%$ anual. Por su parte, la desigualdad medida por el Gini experimentó una caída de más de 6 puntos: desde 52.2 en 2003 a 45.7 en 2007.

El período 2007-2011 se caracteriza por cambios en la misma dirección, pero de menor magnitud. Si bien el ingreso creció y la desigualdad se redujo, ambas variables lo hicieron a un ritmo más moderado. La velocidad de crecimiento del ingreso equivalente pasó del $9.4 \%$ al $2.1 \%$ anual; mientras que la reducción de la desigualdad se desaceleró desde más de 1.6 puntos anuales a 0.9 puntos del Gini por año.

Finalmente, tanto la desigualdad como el crecimiento del ingreso familiar se estancaron durante la etapa 2011-2015. La caída del coeficiente de Gini se redujo a un ritmo de 0.4 puntos promedio por año, menos de la mitad que en la etapa anterior, mientras que el ingreso medio de hecho cayó en términos reales, a un ritmo anual del $1 \%$.

\section{III.2 Resultados de la descomposición}

Los resultados de la descomposición se presentan en la Tabla 2 para distintos indicadores de indigencia y pobreza, y se ilustran para la tasa de incidencia en las Figuras 5 y 6.

La fuerte reducción de la pobreza durante el período 2003-2007 es el producto de los dos efectos - crecimiento y redistribución - operando con intensidad y en el mismo sentido. La tasa de pobreza cayó casi 21 puntos en esos cuatro años: si la desigualdad no hubiera cambiado en ese período, la pobreza de cualquier forma habría caído cerca de 15 puntos por efecto del crecimiento neutral. La caída experimentada en la desigualdad contribuyó con aproximadamente 6 puntos adicionales a la fuerte reducción de la pobreza. La preeminencia del efecto crecimiento sobre el redistributivo se repite en los demás indicadores de pobreza. En el caso de indigencia, el efecto crecimiento también es más alto al considerar la tasa de incidencia, pero su relevancia relativa se reduce en los indicadores que tienen en cuenta la brecha de la pobreza.

Aunque su contribución absoluta es menor que en el período previo, la relevancia relativa del efecto redistributivo es mayor en la etapa 2007-2011. Ello 
Tabla 2: Descomposición del cambio en indigencia y pobreza

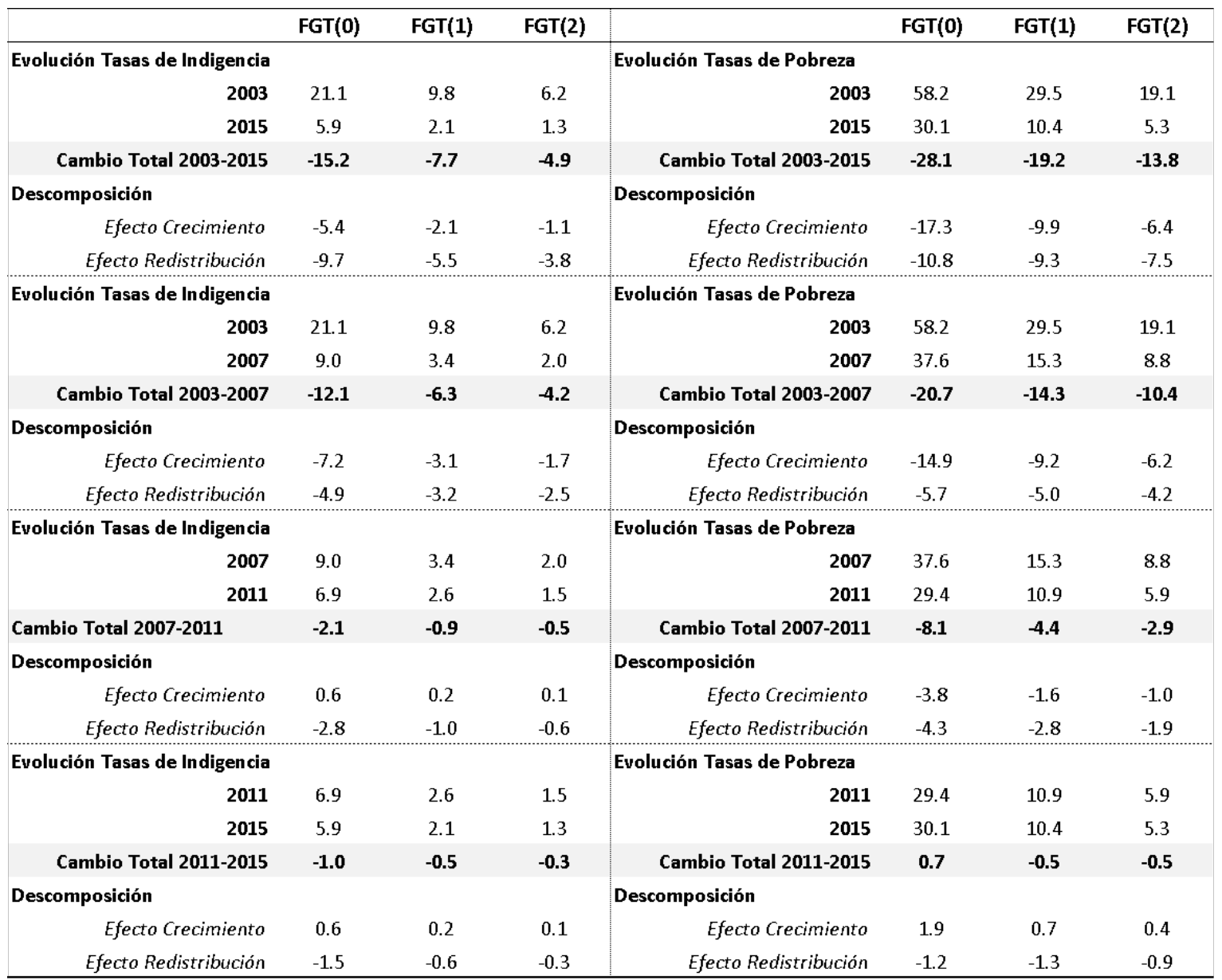

Fuente: Elaboración propia en base a datos de la EPH. 
Figura 5: Descomposición del cambio en la pobreza.

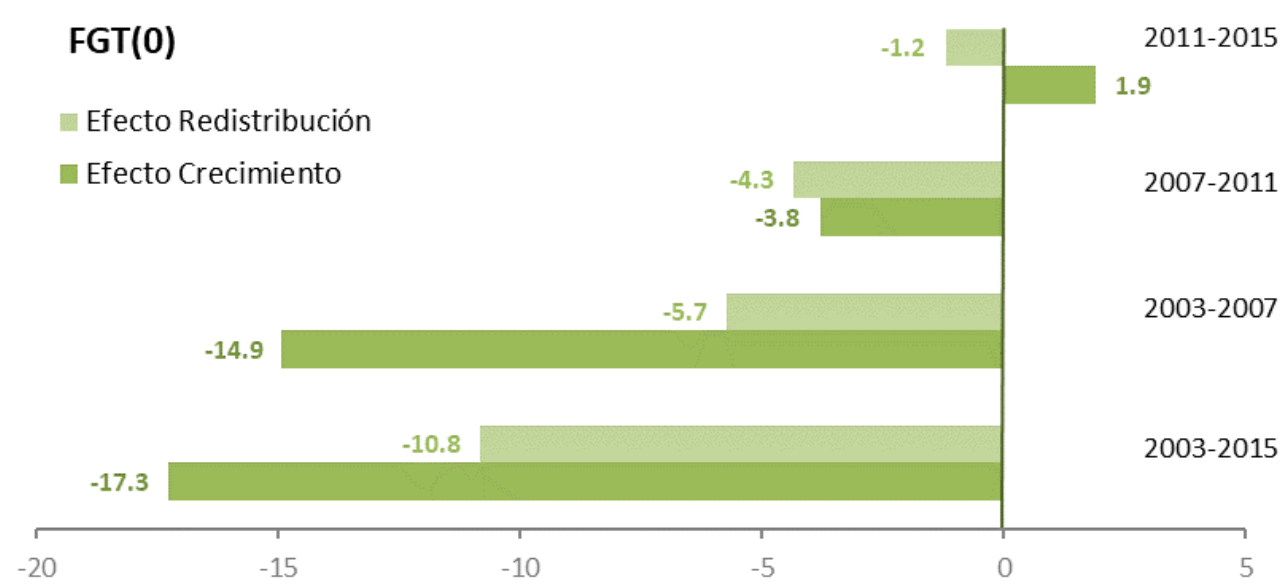

Nota: elaboración propia sobre la base de datos de la EPH.

Figura 6: Descomposición del cambio en la indigencia.

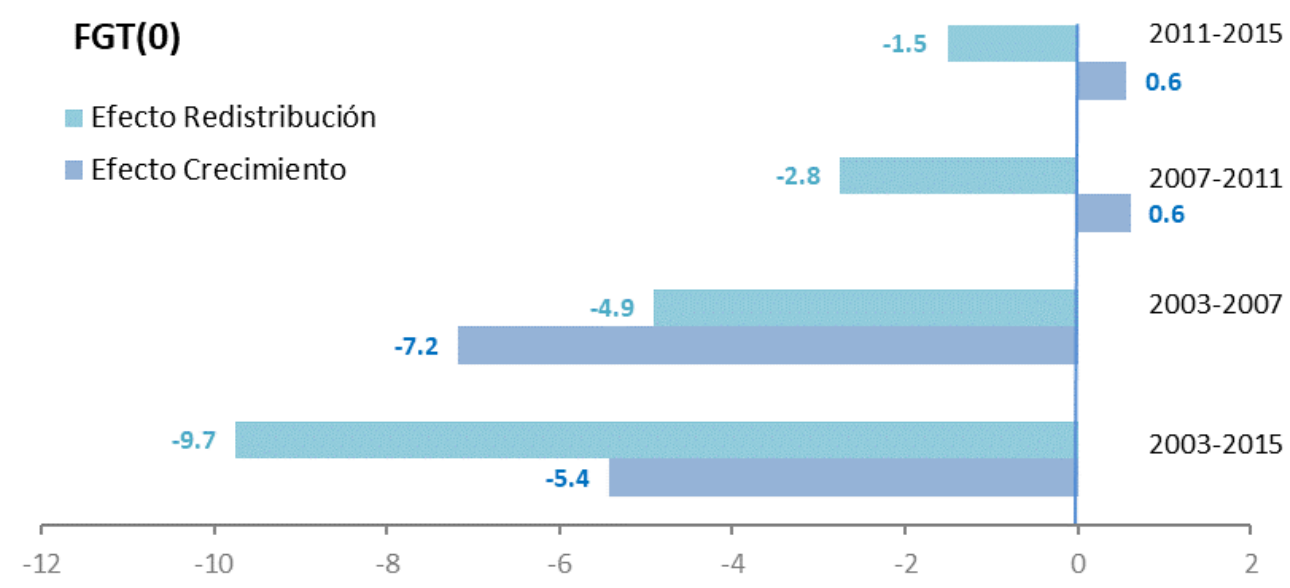

Nota: elaboración propia sobre la base de datos de la EPH. 
obedece a que el aporte a la reducción de la incidencia de la pobreza del efecto crecimiento es significativamente más bajo en este período que en el anterior: 1 punto anual, en comparación con los casi 4 puntos por año del período 20032007. La importancia relativa del efecto redistribución sobre el crecimiento en este período se magnifica al considerar indicadores de pobreza basados en la brecha $^{8}$.

En el último período, 2011-2015, los dos efectos operaron en direcciones contrapuestas: por un lado la desigualdad se redujo, lo que implicó un efecto redistributivo negativo (es decir, reductor de la pobreza), y por el otro el ingreso real se contrajo, lo cual implicó un efecto crecimiento que traccionó la pobreza al aumento. Ambos efectos fueron ligeros y se contrarrestan en el agregado. En la tasa de incidencia prevalece el efecto crecimiento (en este caso, incrementando la pobreza), mientras que en el resto predomina el redistributivo (reduciendo la pobreza).

La descomposición para el período completo de estudio sugiere que la gran caída en la pobreza se asocia fundamentalmente al efecto crecimiento, que representa aproximadamente el $60 \%$ para la tasa de pobreza ${ }^{9}$, resultados que van en línea con el trabajo de Inchauste et al (2014). Sin embargo, las descomposiciones revelan patrones muy diferentes al considerar distintas etapas: en la primera ambos efectos operan con intensidad a favor de una reducción de la pobreza, en especial, el efecto crecimiento; en la segunda etapa la intensidad de ambos efectos disminuye significativamente y comienza a predominar el redistributivo, mientras que en la tercera los dos efectos son pequeños y tienden a compensarse, resultando en un estancamiento en la pobreza.

\footnotetext{
${ }^{8}$ Es curioso que el efecto crecimiento tenga signo negativo en la descomposición de pobreza, pero positivo en la descomposición de indigencia. La razón de este contraste proviene del hecho que la descomposición (y en consecuencia el efecto crecimiento) utiliza una variable de ingreso diferente en cada caso: el ingreso equivalente deflactado por la línea de pobreza en un caso, y el ingreso equivalente deflactado por la línea de indigencia en el otro. Durante el período 2007-2011 el primer ingreso creció $8.7 \%$, mientras que el segundo cayó $3.3 \%$, debido al aumento del precio relativo de los alimentos. Entre 2009 y 2011 el IPC alimentos (con el que se ajusta la línea de pobreza) subió $89 \%$, mientras que el IPC general (con el que se ajusta la línea de indigencia) subió $56 \%$.

${ }^{9}$ El peso del efecto crecimiento en el cambio en la brecha y severidad de la pobreza es algo menor: $52 \%$ y $46 \%$, respectivamente.
} 


\section{Explorando los cambios en la distribución}

La descomposición de la sección anterior, que aísla los efectos del crecimiento y la desigualdad en la evolución de la pobreza, muestra que ambos factores influyeron significativamente en la caída de la pobreza entre 2003 y 2015. Como ya fue señalado, en la realidad esos factores influyen en forma simultánea e incluso interactúan. En esta sección se avanza en una caracterización más detallada de los cambios en la distribución del ingreso que provocan esas interacciones. En la sub-sección 4.1 se presenta y discute brevemente una descomposición por fuentes del crecimiento del ingreso de cada decil. Por su parte, la sub-sección 4.2 propone una descomposición para evaluar la relevancia relativa de las distintas fuentes de ingreso en la evolución de la desigualdad total. Las sub-secciones 4.3 y 4.4 tratan por separado el impacto de cambios en los ingresos laborales y no laborales en la distribución del ingreso, mientras que la sub-sección 4.5 propone un ejercicio para caracterizar el impacto de los cambios en un factor demográfico: el número de hijos.

\section{IV.1 El crecimiento del ingreso por fuentes}

Las Figuras 7, 8 y 9 presentan la descomposición del crecimiento acumulado del ingreso total de los hogares de cada decil en cada uno de los sub-períodos en que se dividió el análisis de este trabajo. El panel superior de cada una de esas figuras muestra el crecimiento del ingreso de cada decil y del total de la población, mientras que el panel inferior lo descompone en el ingreso por fuentes.

Existen notorias diferencias entre períodos en las tasas de crecimiento del ingreso, tanto para el total de la población como por deciles. Como ya fue comentado, la mayor parte del crecimiento del ingreso en 2003-2015 ocurrió en la primera etapa, 2003-2007, mientras que la etapa siguiente aportó algo más de crecimiento y en la etapa final, 2011-2015, se observó una retracción en los ingresos para el promedio de la población.

Una característica común en las tres etapas es la relación negativa entre nivel de ingreso promedio del decil y tasa de crecimiento promedio del ingreso del decil: en los tres casos se verifica que la tasa de crecimiento es mayor cuanto menor el ingreso del decil. De cualquier modo, en 2003-2007 todos los deciles 
Figura 7: Crecimiento del Ingreso por Decil y Descomposición por Fuentes. 2003-2007.
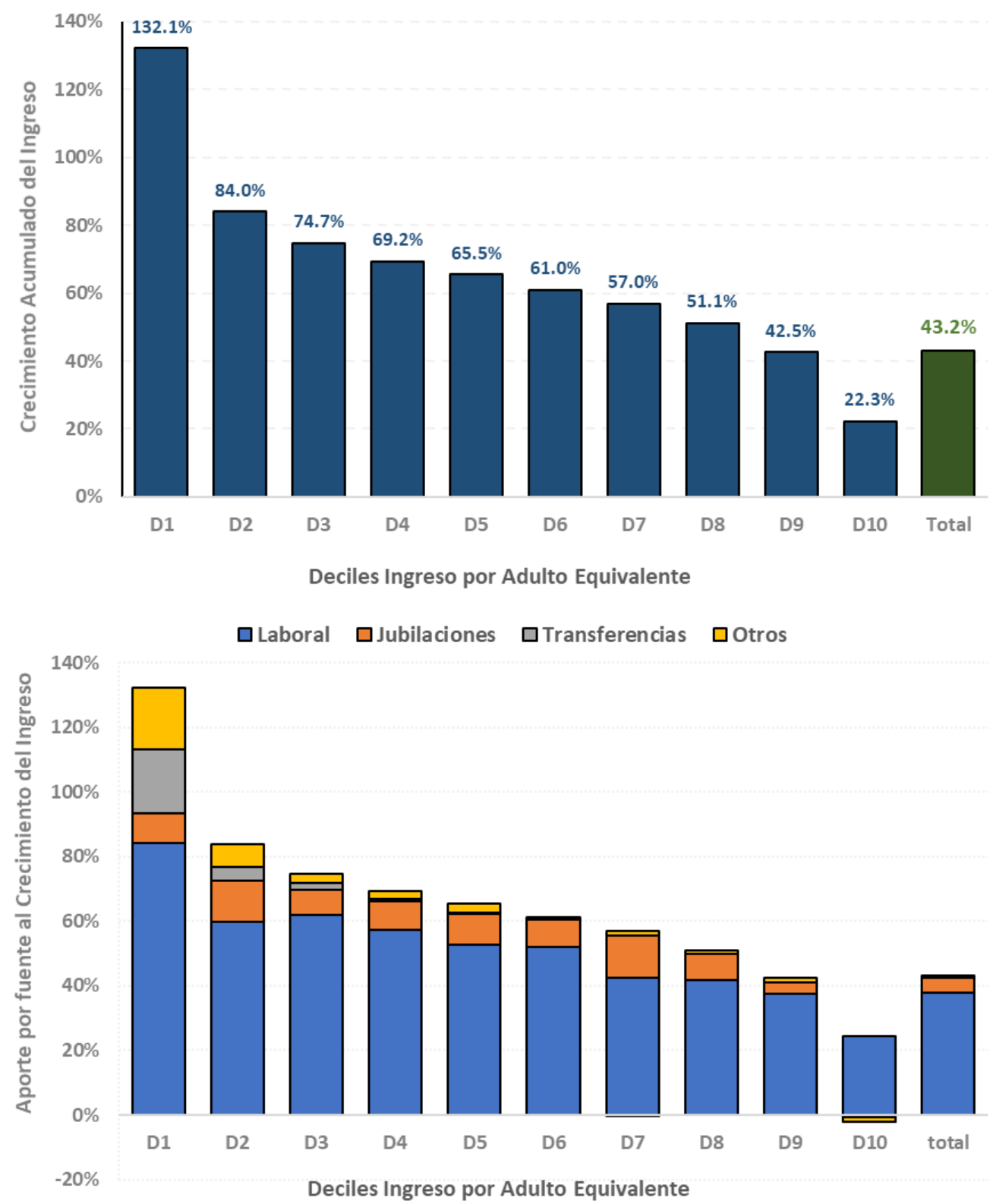

Nota: elaboración propia sobre la base de datos de la EPH. 
Figura 8: Crecimiento del Ingreso por Decil y Descomposición por Fuentes. 2007-2011.
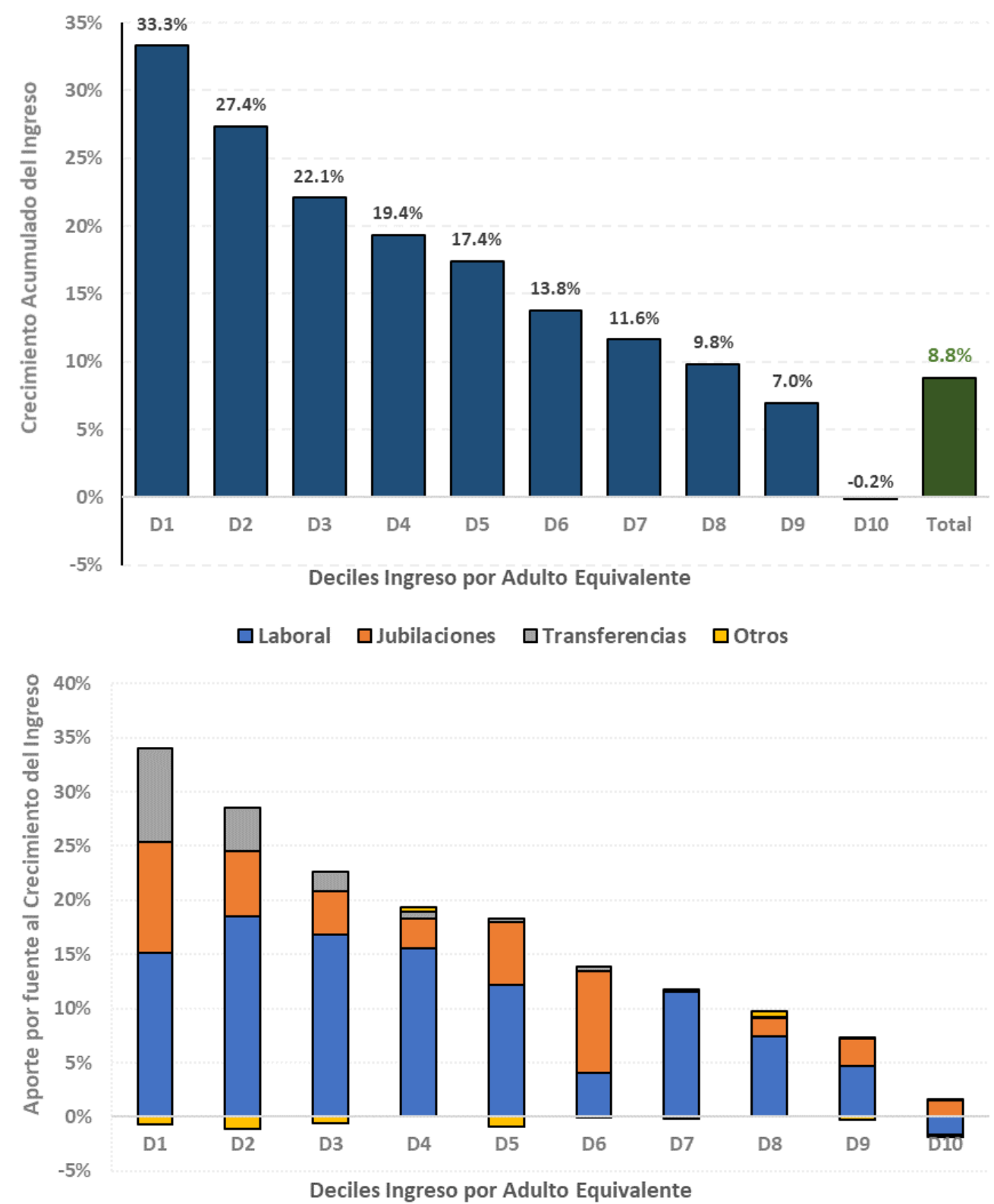

Nota: elaboración propia sobre la base de datos de la EPH. 
muestran tasas positivas de crecimiento, situación que se modifica en las etapas siguientes: en 2007-2011 el decil más rico experimenta un estancamiento en su nivel de ingreso, mientras que en 2011-2015 únicamente crece el ingreso de los dos deciles más pobres.

La relación negativa entre el nivel de ingreso del decil y la tasa de crecimiento del ingreso naturalmente implica una reducción en la desigualdad. Los paneles inferiores de cada una de las figuras muestran la forma en que el movimiento de esas fuentes afectó tanto el crecimiento como la desigualdad. Algunos resultados interesantes que allí se identifican, y cuyo análisis será profundizado en los siguientes apartados de esta sub-sección son los siguientes: 1) la preponderancia que tienen los ingresos laborales en los movimientos en la distribución del ingreso; 2) la importancia de los ingresos por jubilaciones y pensiones y por transferencias estatales para los hogares de menores ingresos, particularmente en el período 2007-2011;3) el deterioro del mercado laboral que se refleja en la evolución de los ingresos durante el último período; y 4) la importante contribución a los ingresos de los hogares de los deciles intermedios y superiores que tuvieron las jubilaciones y pensiones en la última etapa. A continuación se analizarán con más detalle cada una de esas fuentes.

\section{IV.2 Descomposición por fuentes}

La evidencia presentada en la sección previa indica que la desigualdad en la distribución del ingreso se redujo considerablemente en el período 2003-2015. Una característica de ese proceso fue que la velocidad a la que disminuyó la desigualdad no fue constante, sino que con el paso del tiempo se verificó una clara desaceleración en las mejoras, desde avances rápidos en los primeros años del período hasta estancamiento en los años finales del mismo.

Dado que en ese período se observaron diferencias tanto en las condiciones económicas generales como en las políticas específicas que se aplicaron, es esperable que las etapas en las que se dividió el período difieran en otras dimensiones más allá de la velocidad a la que se redujo la desigualdad. Un aspecto importante en el que también puede existir heterogeneidad entre las etapas es en las contribuciones cuantitativas de las distintas fuentes de ingreso a la evolución de la desigualdad total.

En esta sub-sección se busca cuantificar esas contribuciones a partir de 
Figura 9: Crecimiento del Ingreso por Decil y Descomposición por Fuentes. 2011-2015.
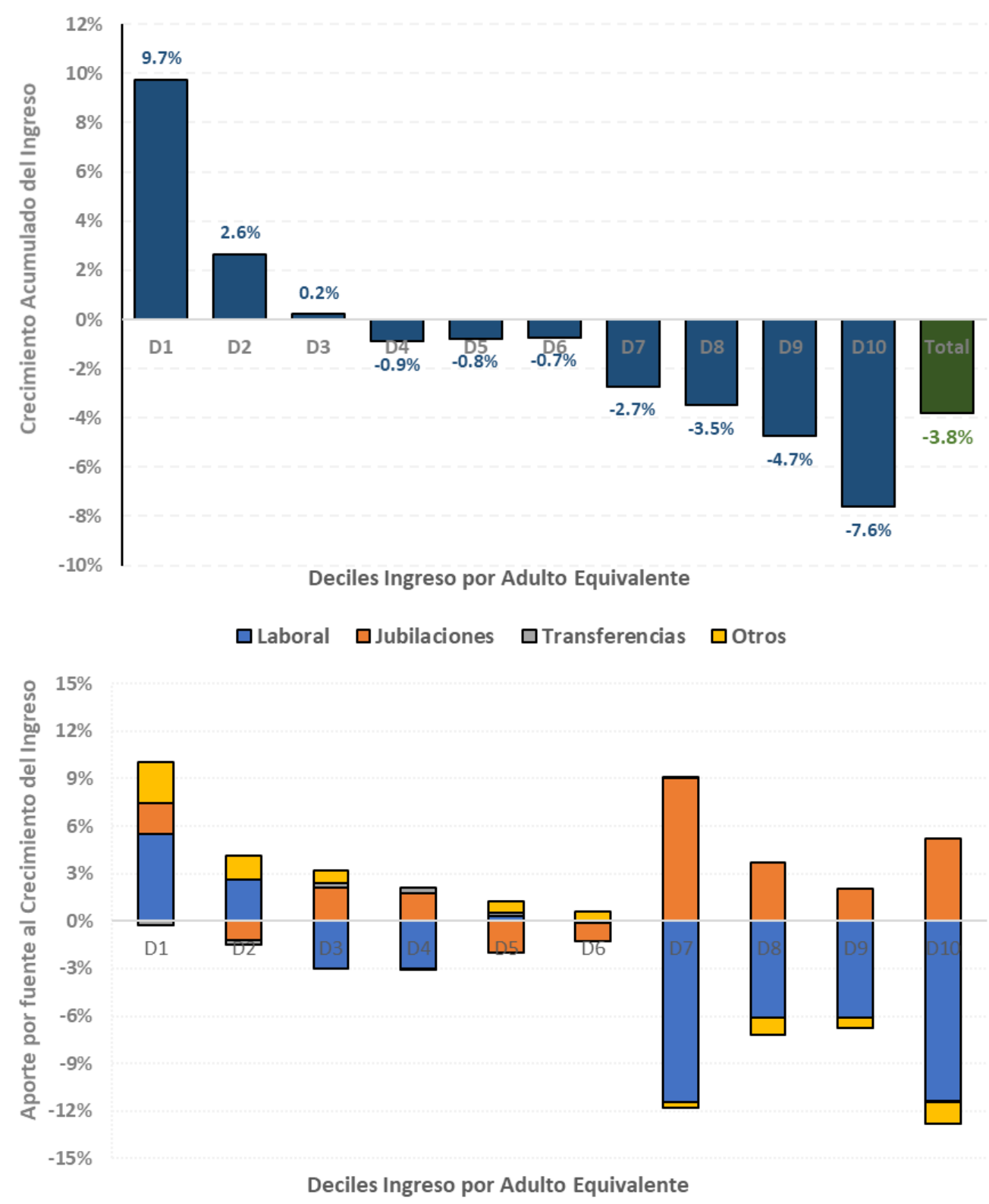

Nota: elaboración propia sobre la base de datos de la EPH. 
un ejercicio basado en simulaciones contrafácticas. Más precisamente, la metodología que se sigue es la propuesta por Azevedo et al. (2012), que extiende la descomposición desarrollada por Barros, Carvalho, Franco y Mendonça (2006). Esta metodología permite aproximar las contribuciones relativas de ingresos laborales y no laborales en la evolución de la desigualdad en la distribución del ingreso. El ingreso familiar por adulto equivalente, la medida de bienestar utilizada en Argentina en las estimaciones de pobreza, se escribe en este caso como la suma de distintas fuentes de ingreso: ingresos laborales e ingresos no laborales, entre los que se distinguen jubilaciones, ingresos por transferencias estatales y otros ingresos no laborales ${ }^{10}$. La simulación consiste en determinar cuál hubiese sido el ingreso por adulto equivalente en el período $\mathbf{t}_{1} \mathrm{si}$, por ejemplo, la distribución de ingresos por jubilaciones hubiese sido la correspondiente a la de $\mathbf{t}_{\mathbf{2}}$. Para cada distribución contrafáctica obtenida, es posible calcular un índice de desigualdad, por lo que el impacto del cambio en cada componente se calcula como la diferencia entre los contrafácticos acumulados para un orden determinado de cambios en las fuentes (ver Apéndice).

Una vez más es importante enfatizar que estas descomposiciones no identifican efectos causales, pero son útiles para identificar regularidades empíricas y analizar qué factores son más importantes cuantitativamente para describir los cambios en la distribución del ingreso.

\section{IV.2.1 Resultados}

La Figura 10 contiene los resultados de la descomposición del cambio en la desigualdad entre fuentes de ingresos, tanto para 2003-2015 como para cada uno de las etapas analizadas en las que se dividió el período. La altura de las barras indica la magnitud de la reducción en la desigualdad en cada etapa y refleja un resultado ya mencionado: la desigualdad disminuyó en todos los períodos, pero

\footnotetext{
${ }^{10}$ La fuente “otros ingresos no laborales” está conformada por las siguientes categorías: ingresos por indemnización por despido, ingreso por alquiler de propiedades, ingreso por ganancias de negocio en el que no trabajó, ingreso por intereses de plazo fijo o rentas de inversiones, ingreso por cuotas de alimentos o ayuda en dinero de otros hogares, ingreso por trabajo de menores de 10 años y otros ingresos en efectivos. Aunque se trata de ingresos de distinta naturaleza, los mismos fueron agrupados en una única variable al representar porcentajes pequeños de los ingresos totales que obtienen los hogares entrevistados en la EPH.
} 
con una clara tendencia hacia la desaceleración en las mejoras.

Figura 10: Descomposición del cambio en la desigualdad.
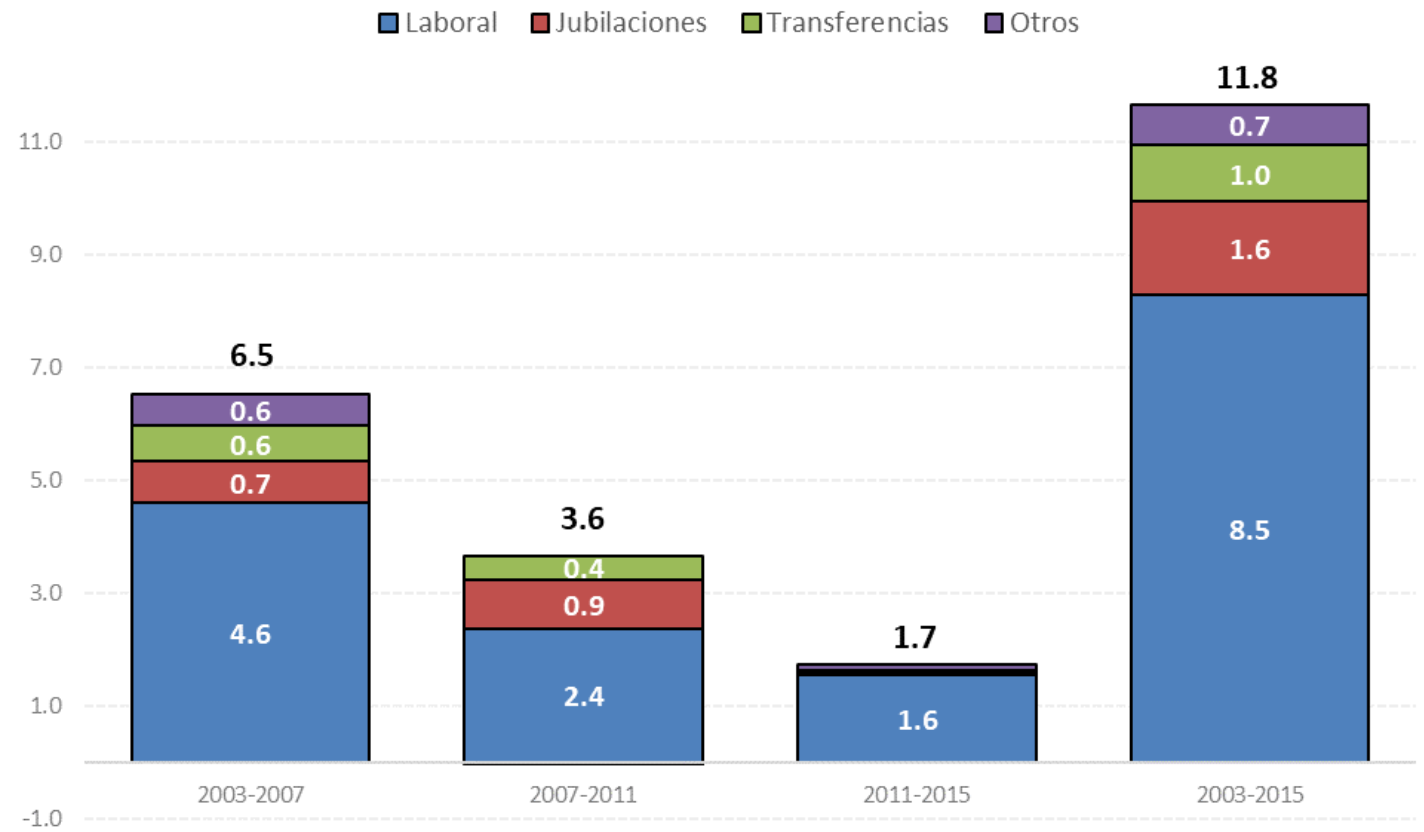

Nota: elaboración propia sobre la base de datos de la EPH.

La contribución de las distintas fuentes de ingresos a la reducción en el coeficiente de Gini se captura en los distintos colores en los que se divide cada barra. En todos los períodos la evolución del ingreso laboral por adulto equivalente fue la principal explicación de la reducción en la desigualdad, lo que va en línea con lo encontrado por Lustig y Lopez-Calva (2009), Beccaria et al. (2010), Bertranou y Maurizio (2011) y Trujillo y Villafañe (2011), entre otros. Este es un resultado esperable, dado que el ingreso laboral es la principal fuente de ingreso para la mayoría de los hogares, representando entre $75.5 \%$ y $80.6 \%$ del ingreso familiar total del hogar promedio en los años analizados.

Más específicamente, entre 2003 y 2015 el $71.2 \%$ de la reducción en el coeficiente de Gini ( 8.5 sobre 11.8 puntos) obedeció a la evolución que tuvo 
el ingreso laboral. En 2003-2007 el efecto del ingreso laboral en la baja en la desigualdad fue similar al del período completo (70.6\%, o 4.6 sobre 6.5 puntos), en 2007-2011 fue algo menor (65.6\%, o 2.4 sobre 3.6 puntos), mientras que en 2011-2015 su influencia relativa fue más importante que en los años anteriores, al explicar casi toda la caída en la desigualdad ( $90.5 \%$, o 1.6 sobre 1.7 puntos).

La Figura 10 sugiere que la evolución del ingreso por jubilaciones fue el segundo aspecto que más contribuyó a la reducción de la desigualdad en 20032015, representando el $14.1 \%$ de la caída en el coeficiente de Gini en esos años (1.6 sobre 11.8 puntos). El importante papel de las jubilaciones en la caída de la desigualdad ha sido documentado también en Beccaria et al (2010) y Bertranou y Maurizio (2011), entre otros. Tanto en términos absolutos como relativos, la etapa donde mayor fue la influencia de esta fuente de ingresos fue 2007-2011, donde representó el $23.7 \%$ de la caída en la desigualdad (0.9 sobre 2.4 puntos). En 2003-2007 la evolución de los ingresos jubilatorios aportó 0.7 puntos de los 6.5 puntos de baja en el coeficiente de Gini (11.4\%), mientras que en 2011-2015 su contribución a la reducción de la desigualdad fue muy pequeña, explicando apenas el $2.6 \%$ del cambio observado.

La evolución de los ingresos por transferencias estatales fue, en ordenes de magnitud, el tercer factor explicativo de la reducción en la desigualdad: contribuyó con el $8.7 \%$ (1 sobre 11.8 puntos) de la caída en el coeficiente de Gini. En términos absolutos, el aporte de esta fuente fue mayor en 20032007 (0.6 puntos) que en 2007-2011 (0.4 puntos), pero en términos relativos la contribución fue mayor en el segundo período que en el primero: $11.2 \%$ (0.4 sobre 3.6 puntos) versus $9.6 \%$ (0.6 sobre 6.5 puntos). Por su parte, entre 2011 y 2015 la evolución de los ingresos por transferencias estatales prácticamente no influyó en la reducción de la desigualdad, siendo su aporte de apenas un $0.9 \%$.

Finalmente, la evolución de los restantes ingresos no laborales también aportó a la reducción de la desigualdad en el período analizado: $6.0 \%$ de la caída en el valor del coeficiente de Gini entre 2003 y 2015 es explicada por dicha evolución. Casi la totalidad de su contribución se concentró en la primera etapa, donde contribuyó con el $8.5 \%$ (0.6 sobre 6.5 puntos) de la caída en la desigualdad, siendo su aporte en las siguientes etapas prácticamente nulo. 


\section{IV.3 Ingresos laborales}

En esta sub-sección se exploran en detalle los cambios en la desigualdad provenientes de la evolución del mercado laboral. Con ese objetivo, se aplica la metodología de descomposiciones microeconométricas propuesta por Bourguignon et al. (2005) y adaptada por Gasparini et al. (2005). Esta metodología permite medir cuánto del cambio en la desigualdad en un período se asocia con cambios en características personales de los trabajadores, cuánto con cambios en los retornos a esas características y cuánto a variaciones en factores no observables y sus retornos. De forma similar a la metodología empleada en la sub-sección anterior, se evalúa qué hubiese ocurrido con el ingreso familiar por adulto equivalente si alguno de los determinantes del ingreso laboral hubiese sido en $\mathbf{t}_{\mathbf{1}}$ el correspondiente a $\mathbf{t}_{2}$, ceteris paribus.

$\mathrm{El}$ ingreso laboral se define en el modelo como el producto del salario horario del trabajador y la cantidad de horas que éste dedica al mercado laboral. Esta fuente de ingreso depende de un conjunto de características de los trabajadores y de sus retornos, tanto observables como inobservables. En particular, este apartado analiza el cambio en el coeficiente de Gini del ingreso equivalente producido por variaciones en características observables de los trabajadores, como cambios en la estructura educativa (efecto "educación"), al igual que cambios en los retornos a ciertas características usualmente discutidas en la literatura. Entre estas últimas, existen escenarios en los que los contrafácticos son creados a partir de cambios en los determinantes del salario horario del trabajador y otros en los que las modificaciones provienen de cambios en determinantes de la decisión de horas trabajadas. En este ejercicio se simulan, dentro del primer grupo, el cambio en los retornos a la educación (efecto "retornos a la educación") y en la brecha salarial de género (efecto "brecha de género"). Una simulación más general y que incluye a las dos anteriores es la resultante de cambiar todos los determinantes de la ecuación del salario horario (efecto "constante"), que se vincula con cambios más generales, no relacionados directamente con las características de los trabajadores. Por otro lado, dentro del grupo de simulaciones que involucran el cambio de los determinantes de las horas trabajadas, se realizan las del efecto "horas" y efecto "empleo". Si bien

ambas simulaciones comprenden cambios similares en las decisiones laborales de los trabajadores, en la primera se capta la variación en el ingreso que se 
hubiese producido si la cantidad de horas trabajadas en $\mathbf{t}_{\mathbf{1}}$ hubieran sido las de $\mathbf{t}_{2}$, sin posibilidad de cambios en la situación laboral, mientras que la segunda simulación aísla solo el impacto de cambios en el status laboral entre empleado y no empleado o viceversa, ignorando cambios en las demás variables laborales (horas trabajadas o salarios). Finalmente, la última simulación corresponde a cambios en aquellos factores (y sus retornos) que afectan el salario horario pero que no pueden observarse o medirse (efecto "inobservables"). Los detalles metodológicos de estos ejercicios se encuentran en el Apéndice del trabajo.

\section{IV.3.1 Resultados}

La descomposición requiere estimar modelos de salarios horarios y horas trabajadas. La Tabla A.1 muestra los resultados de las regresiones de Mincer del logaritmo del salario horario. La educación es capturada a través de variables dummies que indican el nivel educativo que posee cada trabajador: primaria completa, secundaria incompleta, secundaria completa, superior incompleto o superior completo, siendo la categoría omitida primaria incompleta. Además, se incluyen en la regresión la edad y su cuadrado, una variable dummy de género y las variables dummies correspondientes a las regiones argentinas ${ }^{11}$. La ecuación de selección del modelo agrega además el estado civil, el número de hijos, la asistencia a un establecimiento educativo, la minoría de edad (menor a 18 años) y la condición laboral del jefe y del cónyuge como determinantes de la decisión de participar o no en el mercado laboral ${ }^{12}$. Las primeras cuatro columnas muestran los coeficientes estimados en cada año para los jefes del hogar, las siguientes cuatro para los cónyuges y las últimas para otros miembros del hogar, todos entre 15 y 65 años. Por su parte, la Tabla A.2 muestra los resultados de la estimación de modelos Tobit de horas trabajadas. Estas regresiones son los insumos básicos para implementar las descomposiciones, cuyos resultados se presentan en la Tabla 3 y se interpretan en el siguiente párrafo.

Entre 2003 y 2007 el coeficiente de Gini de la distribución del ingreso

\footnotetext{
${ }^{11}$ La categoría base del conjunto de dummies de región es "Gran Buenos Aires".

${ }^{12}$ Ver Gasparini et al. (2004) para una discusión sobre la elección de estas variables. En particular, en la ecuación salarial se prefirió no incluir variables del tipo de empleo (ej. sector de actividad, tamaño de la firma, tipo de ocupación) ya que si bien aumentan la capacidad predictiva del modelo pueden confundir el efecto de las variables individuales más exógenas (como la educación) sobre el salario.
} 
Tabla 3: Descomposición de los cambios en el coeficiente de Gini Ingreso por adulto equivalente ajustado por la línea de pobreza moderada

\begin{tabular}{|c|c|c|c|c|}
\hline \multirow[b]{2}{*}{ Cambio observado } & \multicolumn{4}{|c|}{$2003-2007$ 2007-2011 2011-2015 2003-2015 } \\
\hline & -6.5 & -3.6 & -1.7 & -11.8 \\
\hline Constante & -1.32 & -0.17 & -0.64 & -3.63 \\
\hline Retornos a la educación & 0.06 & -0.54 & -0.74 & -1.20 \\
\hline Brecha de género & -0.20 & 0.00 & 0.22 & -0.03 \\
\hline Inobservables & -1.03 & -0.30 & -0.49 & -1.77 \\
\hline Horas & -0.92 & 0.09 & 0.23 & -0.47 \\
\hline Empleo & -0.08 & -0.04 & 0.16 & 0.06 \\
\hline Educación & -0.24 & -0.17 & -0.05 & -0.63 \\
\hline
\end{tabular}

Nota: Descomposición de Bourguignon et al (2005) del coeficiente de Gini, calculado en base al ingreso por adulto equivalente sobre la línea de pobreza. Los cambios en el Gini están multiplicados por 100.

por adulto equivalente se redujo 6.5 puntos. La primera columna de la tabla caracteriza esa dinámica, reportando el efecto de equilibrio parcial que hubieran tenido ciertos cambios en el proceso generador de ingresos, manteniendo constante el resto. El valor para la fila de "retornos a la educación" es 0.06. Ese valor sugiere que si solo los retornos a la educación hubieran cambiado entre 2003 y 2007 (los coeficientes de las dummies educativas en las ecuaciones de salarios), y todo el resto hubiera permanecido constante en el proceso generador de ingresos, entonces la desigualdad, medida por el coeficiente de Gini hubiera aumentado en 0.06 puntos. En síntesis, la descomposición sugiere que el cambio en el premio salarial a la calificación no fue un factor relevante para explicar el fuerte descenso de la desigualdad de ingresos en la primera mitad de los 2000s. Este efecto, en cambio, toma relevancia en los dos subperíodos siguientes: -0.54 entre 2007 y 2011 y - 0.74 entre 2011 y 2015 en el marco de cambios salariales mayores en los estratos de menor calificación.

En contraste con los cambios en los retornos a la educación, el resto de los factores de la primera columna de la Tabla A.2 parecen haber contribuido, aunque con distinta intensidad, a la reducción de la desigualdad entre 2003 y 2007. El efecto "constante" contribuye a esa caída con 1.32 puntos del Gini, un cambio económicamente significativo. Este efecto refleja básicamente el 
fuerte incremento generalizado de los salarios reales en el período de rebote económico post-crisis. De acuerdo a los datos de la EPH, entre 2003 y 2007 el salario real creció un $24.1 \%$ en promedio, con apenas pequeñas variaciones entre grupos educativos. Un aumento generalizado en términos proporcionales del salario horario tiene repercusiones sobre la desigualdad en el ingreso familiar equivalente debido fundamentalmente a que el ingreso laboral es un componente más importante del ingreso familiar en los hogares pobres que en los más afluentes. El efecto "constante" toma un valor negativo, pero menor, en el resto del período bajo estudio.

La reducción en la brecha condicional de género entre hombres y mujeres también contribuyó a la caída de la desigualdad entre 2003 y 2007, aunque el efecto fue menor: apenas 0.20 puntos del Gini. Ese efecto desaparece entre 2007 y 2011 y revierte su signo en la última etapa. En el agregado, la conclusión es que los cambios en la brecha condicional de género fueron menores y no tuvieron un impacto distributivo relevante.

En contraste, el factor "inobservables" contribuyó con casi 2 puntos a la caída total de la desigualdad en el período. Ese factor se corresponde con una marcada reducción de la dispersión del término de error en las ecuaciones de salarios, término que capta características inobservables de los individuos, como la habilidad o los contactos, y sus retornos. El desvío estándar de ese término de error (sigma en la Tabla A.1) cayó de 0.76 en 2003 a 0.62 en 2015 en las ecuaciones de salarios de los jefes de hogar, y lo hizo en magnitudes semejantes en el caso de cónyuges y otros miembros. Trivialmente, es difícil identificar los factores detrás de este efecto. Los resultados de la descomposición sugieren que su impacto no fue insignificante, lo que amerita dedicarle más esfuerzos de investigación.

El impacto de los cambios en el empleo es captado en las descomposiciones mediante dos efectos: el primero se obtiene simulando cambios solo en las horas trabajadas de los trabajadores con empleo, mientras que el segundo aísla los cambios en el status laboral (de empleado a no-empleado o viceversa). Estos efectos son cualitativamente semejantes, aunque más intensos en el caso del factor horas trabajadas ${ }^{13}$. Las fuertes mejoras en el mercado laboral luego de

\footnotetext{
${ }^{13} \mathrm{El}$ efecto empleo tiene el signo esperado, pero su magnitud es quizás sorpresivamente baja, considerando la recuperación del empleo en el período. Parte de este resultado puede ser explicado por el carácter generalizado de esta recuperación, luego de una recesión profunda que afectó a
} 
la crisis macroeconómica de 2001/2002 se tradujeron en un aumento tanto del empleo como de las horas trabajadas de toda la población, pero especialmente de los trabajadores menos calificados, lo que contribuyó a una reducción de la desigualdad de ingresos. De acuerdo a la descomposición estos efectos contribuyen con alrededor de un punto del Gini a esa caída. Las condiciones se revierten en el resto del período bajo estudio: de hecho los efectos horas y empleo toman signos positivos, denotando un efecto distributivo desigualador.

La estructura educativa en Argentina ha ido cambiando a lo largo del tiempo (Tabla 4). Mientras que la proporción de trabajadores con secundaria incompleta o menos se redujo entre 2003 y 2015, la proporción de aquellos con algún grado de educación superior se expandió. De cualquier forma, la mayor expansión se produjo en el grupo de los que tienen secundaria completa: su participación aumentó de $20 \%$ a $27 \%$ entre 2003 y 2015. El efecto "educación" en la descomposición de la Tabla 3 resultó negativo a lo largo del período, aunque relativamente pequeño y decreciente. En síntesis, la expansión educativa que experimentó el país durante este período contribuyó a una reducción de la desigualdad de ingresos, aunque su aporte fue bajo y decreciente ${ }^{14}$.

En resumen, aunque son muchos los factores que se conjugaron en la fuerte caída de la desigualdad entre 2003 y 2007, la descomposición resalta dos de ellos: el aumento generalizado de los salarios horarios reales y la recomposición del empleo, especialmente entre los no calificados. También en estos años hacen una contribución igualadora la compresión salarial en términos de algunos factores observables (género) e inobservables y la expansión educativa. Estos efectos se minimizan o directamente desaparecen en el resto del período. En su lugar, aporta a la caída de la desigualdad la compresión salarial asociada a una reducción de la brecha salarial por educación.

todos los trabajadores. Este es de cualquier forma un punto que merece un análisis más detallado en un próximo trabajo.

${ }^{14}$ Es importante remarcar que el efecto "educación" de esta sección es una estimación del impacto directo que hubiera tenido un cambio en la estructura educativa como el observado sobre la distribución del ingreso, caeteris paribus, lo que implica ausencia de impacto sobre la estructura salarial. Nuestros resultados sugieren que ese efecto es igualador, pero bajo y decreciente. Naturalmente, la expansión educativa, con el consiguiente aumento de la oferta de trabajo calificado, podría haber contribuido a una reducción del premio salarial por calificación y por consiguiente a la desigualdad laboral. El efecto "retornos a la educación" en la Tabla 5 debería captar este efecto (combinado con el de otros factores que afectan la estructura salarial). 
Tabla 4: Ocupados por nivel educativo.

\begin{tabular}{lcccc}
\hline \hline & \multicolumn{4}{c}{ Promedio } \\
\cline { 2 - 5 } & 2003-II & 2007-I & 2011-I & $2015-\mathrm{I}$ \\
\hline Primaria incompleta & 6.9 & 5.8 & 4.3 & 3.9 \\
Primaria completa & 22.2 & 20.4 & 18.1 & 17.0 \\
Secundaria incompleta & 19.0 & 17.7 & 17.4 & 16.9 \\
Secundaria completa & 20.2 & 22.7 & 24.6 & 26.9 \\
Superior incompleto & 13.4 & 14.0 & 14.3 & 13.8 \\
Superior completo & 18.2 & 19.4 & 21.2 & 21.5 \\
\hline
\end{tabular}

Nota: Porcentaje de ocupados entre 15 y 65 años por nivel educativo, con respuestas válidas.

Fuente: Elaboración propia en base a datos de la EPH.

\section{IV.4 Ingresos no laborales}

En esta sub-sección se estudia en mayor detalle la evolución de las distintas fuentes de ingresos no laborales y su rol en la reducción de la desigualdad.

\section{IV.4.1 La evolución de los ingresos por jubilaciones y pensiones}

De acuerdo a información de la EPH los ingresos por jubilaciones y pensiones son, por detrás del ingreso laboral, la segunda fuente de ingreso más importante de los hogares argentinos: en el período bajo análisis representaron entre $13.9 \%$ y $19.4 \%$ del ingreso familiar por adulto equivalente. En ese sentido, no resulta sorpresivo que la evolución de esta fuente de ingresos sea la segunda explicación más importante del cambio en la desigualdad entre 2003 y 2015.

En el comienzo del período, en 2003, el ingreso por jubilaciones y pensiones representaba el $15.3 \%$ del ingreso por adulto equivalente y tenía una distribución desigual. El panel superior izquierdo de la Figura 11 muestra que el $62.0 \%$ de los adultos mayores contaba con ingresos de esta fuente, pero que mientras en el decil más pobre la cobertura alcanzaba a apenas el $11 \%$ de los adultos mayores, en los 5 deciles más ricos la misma era de al menos $66 \%$. La Tabla 5 confirma la elevada desigualdad en la distribución de este concepto de ingreso: mientras el coeficiente de Gini de la distribución del ingreso por adulto equivalente era 
0.522 en 2003, el Índice de Concentración (IC) del ingreso por jubilaciones y pensiones ascendía a 0.579 .

Tabla 5: Coeficiente de Gini del Ingreso por Adulto Equivalente. Índices de Concentración de las distintas Fuentes de Ingreso

\begin{tabular}{cccccc}
\hline \hline & $\begin{array}{c}\text { Coeficiente de Gini } \\
\text { Ingreso por Adulto } \\
\text { Equivalente }\end{array}$ & Ingreso Laboral & $\begin{array}{c}\text { Ingreso por } \\
\text { Jubilaciones } \\
\text { Pensiones }\end{array}$ & $\begin{array}{c}\text { Índice de Concentración } \\
\text { Ingresos por } \\
\text { Estatales }\end{array}$ & $\begin{array}{c}\text { Otros Ingresos no } \\
\text { Laborales }\end{array}$ \\
\hline 2003 & $\mathbf{0 . 5 2 2}$ & 0.505 & 0.579 & -0.231 & 0.670 \\
2007 & $\mathbf{0 . 4 5 7}$ & 0.459 & 0.474 & -0.433 & 0.508 \\
2011 & $\mathbf{0 . 4 2 1}$ & 0.426 & 0.424 & -0.402 & 0.520 \\
2015 & $\mathbf{0 . 4 0 4}$ & 0.399 & 0.467 & -0.435 & 0.423 \\
\hline
\end{tabular}

Fuente: Elaboración propia en base a datos de la EPH.

Entre 2003 y 2007 ocurrieron varias modificaciones respecto al ingreso por jubilaciones y pensiones: su tasa de crecimiento fue menor a la del promedio de los otros ingresos (por lo que su participación en el ingreso por adulto equivalente cayó de $15.3 \%$ a $13.9 \%$ ), pero en simultáneo se experimentó un crecimiento en el porcentaje de adultos mayores que recibían este ingreso, y también su distribución se volvió algo más igualitaria. De acuerdo a la EPH, entre 2003-II y 2007-I el porcentaje de adultos mayores que recibía este ingreso creció de $62 \%$ a $72.1 \%$ (panel superior derecho de la Figura 4.3$)^{15}$. Este crecimiento se explica por la aplicación desde finales de 2005 de la Ley 25994 de jubilación anticipada, la que permitió a varones de 60 a 64 años y mujeres de 55 a 59 años que estaban sin empleo al 30/11/2004 acceder a un beneficio cuyo valor era la mitad del haber jubilatorio que percibirían una vez llegada la edad de retiro (65 y 60 años, respectivamente). Aunque la distribución de jubilaciones y pensiones continuó siendo desigual, existió una clara mejoría distributiva, la que se confirma en la Tabla 5: el IC del ingreso de jubilaciones y pensiones cayó de 0.579 a 0.474 entre 2003 y 2007. Como resultado de la combinación de una caída en la participación en el ingreso total y una mejora en su distribución, entre

\footnotetext{
${ }^{15}$ Estos porcentajes están en línea con lo reportado en los datos administrativos de ANSES, que muestran un aceleramiento de la cobertura previsional entre finales de 2005 y finales de 2007.
} 
EXPLORANDO LOS CAMBIOS DE LA POBREZA EN ARGENTINA: 2003-2015 101

Figura 11: Porcentaje de Individuos que Reciben Ingresos por Jubilaciones y Pensiones por Decil Mujeres de 60 y más años, Varones de 65 y más años.
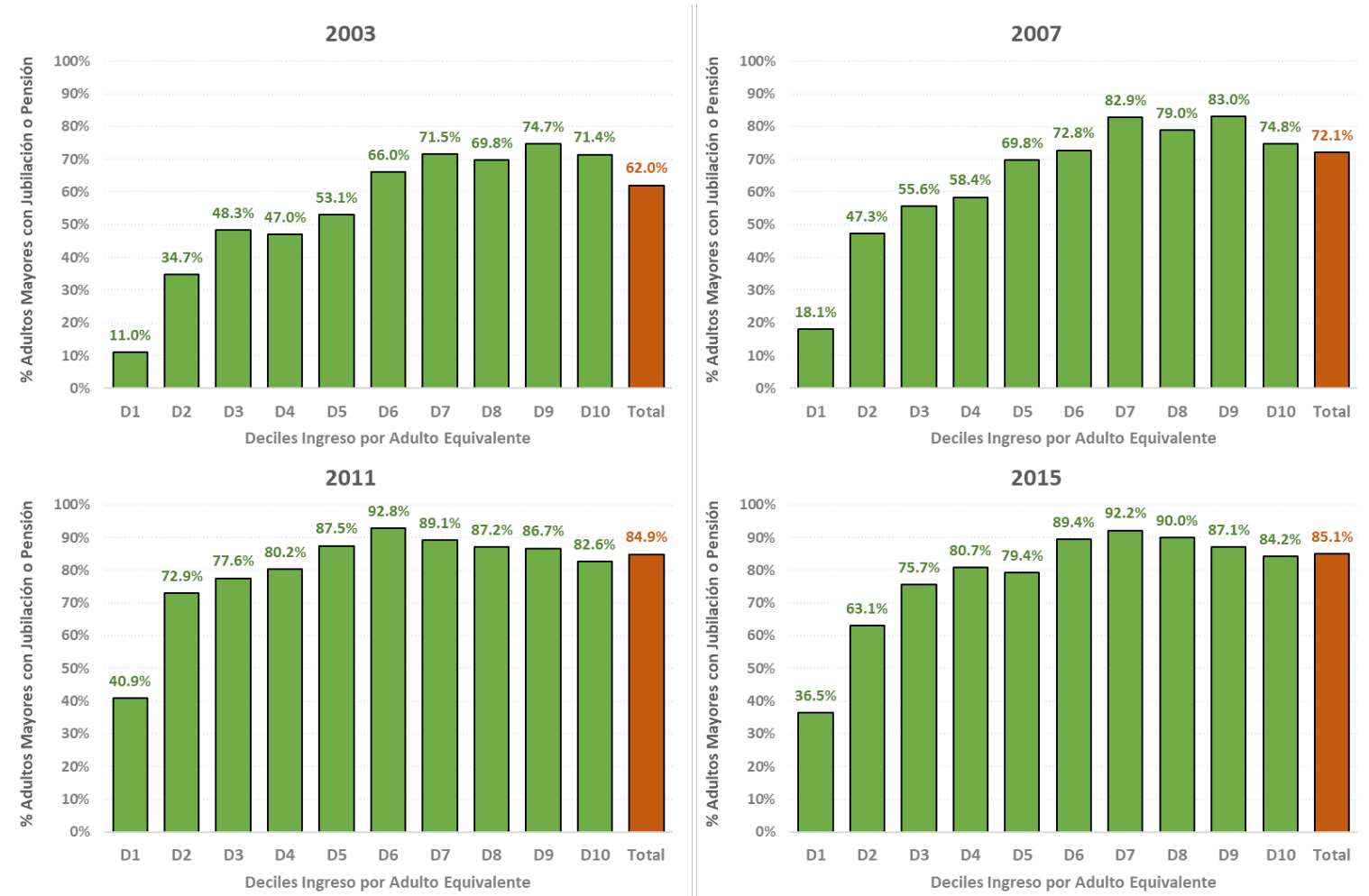

Nota: elaboración propia sobre la base de datos de la EPH. 
2003 y 2007 el ingreso por jubilaciones y pensiones contribuyó con una caída de 0.7 puntos en el coeficiente de Gini (Figura 10).

El porcentaje de adultos mayores con cobertura previsional creció aún más después de 2007-I: según el panel inferior izquierdo de la Figura 11 esa cobertura llego a $84.9 \%$ en 2011-I. Ese crecimiento siguió obedeciendo principalmente a la moratoria previsional producto de la Ley 25994, la que siguió abierta hasta abril de 2008. Este fuerte crecimiento en la cobertura, conjuntamente con una desaceleración en el crecimiento de otro tipo de ingresos significó que en este período el ingreso por jubilaciones y pensiones aumentó su participación en el ingreso total (de $13.9 \%$ a $15.4 \%$ ). También continuó mejorando la distribución de esta fuente de ingresos: el IC del ingreso por jubilaciones y pensiones disminuyó de 0.474 a 0.424 entre 2007 y 2011. De este modo, la mejora distributiva y el incremento de la participación del ingreso por jubilaciones y pensiones en el ingreso total entre 2007 y 2011 son factores que ayudan a explicar su contribución a la caída en la desigualdad en ese período. El aporte de este factor a la reducción en el coeficiente de Gini fue de 0.9 puntos (Figura 8).

Finalmente, entre 2011-I y 2015-I la cobertura del sistema previsional entre los adultos mayores se mantuvo estable, con un leve movimiento desigualador (incremento de cobertura en los 4 deciles más ricos, caída de la cobertura en los 3 deciles más pobres). De cualquier modo, la cobertura estable del sistema previsional en un contexto de caída del ingreso por adulto equivalente implicó un crecimiento en la participación del ingreso por jubilaciones y pensiones en el ingreso total (de $15.4 \%$ a $19.4 \%$ ). En relación al sesgo desigualador, el mismo es posiblemente producto de que, ante la no disponibilidad de moratorias previsionales (recién en los últimos meses de 2014 se abrió otra moratoria), la mayor parte de las entradas del régimen previsional en este período fueron en el régimen contributivo, donde normalmente acceden individuos que pertenecen a los deciles superiores de la distribución del ingreso. El IC de este ingreso se incrementó desde 0.424 a 0.467 entre 2011 y 2015. Como resultado de las tendencias descritas en este párrafo, el ingreso por jubilaciones y pensiones no aporta a la reducción de la desigualdad entre 2011 y 2015.

En resumen, la cobertura del sistema previsional entre adultos mayores creció de $62 \%$ a $85.1 \%$ entre 2003 y 2015 , lo que implicó que la participación de esta fuente de ingresos en el ingreso por adulto equivalente se incrementó desde $15.3 \%$ a $19.4 \%$. Dado que esa expansión del sistema previsional fue 
mayormente producto de moratorias que permitieron incorporar al sistema a individuos que no habían podido completar los años de aportes necesarios para recibir una jubilación del sistema contributivo, la misma tuvo características igualadoras: el IC del ingreso por jubilaciones y pensiones cayó desde 0.579 a 0.467 entre 2003 y 2015. La combinación de un sistema más amplio y menos desigual implicó un efecto igualador sobre la distribución del ingreso, estimado en 1.6 puntos del Gini en todo el período bajo análisis.

\section{IV.4.2 La evolución de los ingresos por jubilaciones y pensiones}

Las bases de datos de la EPH disponibles para los usuarios no cuentan, desafortunadamente, con variables que capturen en forma precisa los ingresos provenientes de programas de transferencias estatales como varios de los que funcionaron en el período estudiado: el Plan Jefes y Jefas de Hogar Desocupados (PJJHD), el Programa Familias por la Inclusión Social (FIS) o la Asignación Universal por Hijo para la Protección Social (AUH). Dichos ingresos se encuentran registrados en una variable que incluye varias fuentes de ingreso: "subsidio o ayuda social del gobierno, iglesias, etc." En este trabajo, el ingreso por transferencias estatales se define como el ingreso capturado en esa variable por debajo de un cierto monto, siendo ese umbral definido en base a los valores máximos que otorgaban los programas de transferencias vigentes en cada momento ${ }^{16}$.

Los ingresos por transferencias estatales representaron una proporción muy pequeña del ingreso por adulto equivalente de un hogar promedio: esa proporción fue creciente entre 2003 y 2015, pero nunca llegó a superar el $1.1 \%$ del ingreso de los hogares ${ }^{17}$. Sin embargo, la Figura 10 indica que la contribución de las transferencias estatales a la reducción de la desigualdad en el período

\footnotetext{
${ }^{16}$ Con datos de la EPH de 2016 e información administrativa de ANSES, Sanz (2019) estima que las transferencias reportadas en la EPH son aproximadamente la mitad de las registradas oficialmente.

${ }^{17} \mathrm{Si}$ bien es posible que la EPH subestime estos ingresos, al no ser una encuesta diseñada para medirlos, los datos administrativos de ANSES muestran que se trata de una fuente de ingreso de menor importancia para el promedio de los hogares. Por ejemplo, mientras en 2015 ANSES pagó a los hogares más de 430 mil millones de pesos por prestaciones de Seguridad Social, solamente transfirió 34 mil millones de pesos a los hogares en concepto de la AUH. En otras palabras, por cada peso transferido por AUH se pagaron 12.7 pesos en prestaciones de Seguridad Social.
} 
2003-2015 fue significativamente mayor (alrededor de $10 \%$ en 2003-2007 y 2007-2011, algo menos que $9 \%$ en el período completo) a esa participación en los ingresos totales. Ese resultado se puede deber a dos hechos: 1) se trata de una fuente de ingreso que se distribuye muy en favor de los hogares más pobres, cuya participación en el ingreso por adulto equivalente se incrementó en el período; y/o 2) su impacto distributivo aumentó en forma importante entre 2003 y 2015. Como se verá a continuación, ambos hechos ayudan a explicar lo ocurrido con esta fuente de ingresos.

En 2003 aproximadamente el $4 \%$ de los hogares obtenía ingresos por transferencias estatales (mayormente del PJJHD), los que representaban el $0.6 \%$ del ingreso por adulto equivalente de un hogar promedio. La distribución de este ingreso era igualadora, aunque no eran los hogares del decil más pobre quienes recibían la mayor proporción de esta transferencia, sino los de los deciles 2, 4 y 3 , en ese orden (panel superior izquierdo de la Figura 12). En los dos deciles más ricos menos del $1 \%$ de los hogares se beneficiaban con este tipo de ingreso. La información en la Tabla 5 permite confirmar esta distribución pro-pobre: el IC de este ingreso en 2003 toma valor negativo (-0.231), indicando una distribución fuertemente pro-pobre.

La proporción de hogares que recibió este tipo de ingresos (beneficiarios residuales de PJJHD, nuevos beneficiarios de FIS y de otros programas adicionales implementados por el Ministerio de Desarrollo Social) se incrementó entre 2003 y 2007, llegando a $7.6 \%$ de los hogares (panel superior derecho de la Figura 12), lo que implicó que la participación de esta fuente de ingresos en el ingreso por adulto equivalente creciera (desde $0.6 \%$ a $0.7 \%$ ) aún en un contexto de fuerte crecimiento de los ingresos. En adición a lo ya mencionado, la distribución de este ingreso se volvió claramente más favorable para los hogares de menores ingresos: el porcentaje de hogares beneficiarios en cada decil era claramente decreciente en el ingreso, superando el $20 \%$ de los hogares en los dos deciles más pobres y siendo inferior a $1 \%$ de los hogares en los dos deciles más ricos. El IC pasó de -0.231 en 2003 a -0.433 en 2007. La expansión de la cantidad de hogares con este tipo de ingresos, el crecimiento de la importancia de esta fuente de ingresos en el ingreso total y la mejora en su distribución son factores que ayudan a entender la contribución que tuvo esta fuente de ingresos a la caída de la desigualdad en 2003-2007 (aportando 0.6 puntos a la caída del coeficiente de Gini). Estos resultados coinciden con las conclusiones de Lustig 
Figura 12: Porcentaje de Hogares que Reciben Ingresos por Transferencias Estatales por Decil.
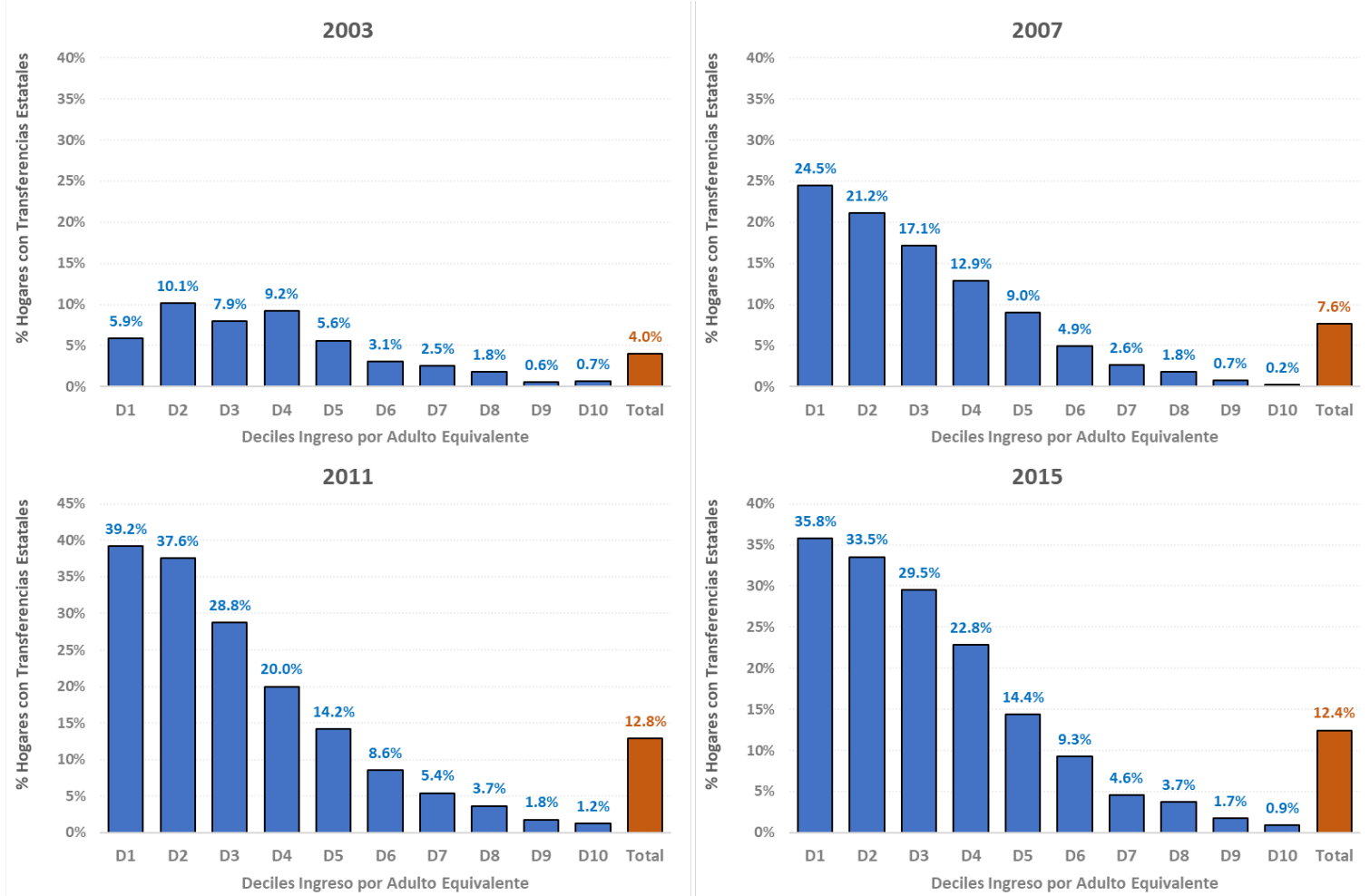

Nota: elaboración propia sobre la base de datos de la EPH. 
y Lopez-Calva (2009).

Entre 2007 y 2011 vuelve a crecer marcadamente el porcentaje de hogares que se beneficia con ingresos por transferencias estatales: el mismo sube a $12.8 \%$ (panel inferior izquierdo en la Figura 12) producto de la implementación de la AUH a finales del 2009. La participación de este tipo de ingreso en el ingreso por adulto equivalente crece de $0.7 \%$ a $1.0 \%$ en el mismo lapso. El porcentaje de hogares que recibe este beneficio se incrementa en todos los deciles, sin que sea claro de la Figura 12 si existió una mejora distributiva importante. De hecho el el IC pasa de -0.433 en 2007 a -0.402 en 2011. Lo que sí está claro es que el incremento en la cantidad de hogares que recibe este ingreso, la suba en su participación en el ingreso por adulto equivalente y la estabilidad en su distribución en favor de los hogares de menores ingresos, son factores que explican el impacto positivo en términos de reducción de la desigualdad que tuvo la evolución de esta fuente de ingresos entre 2007 y 2011. Esta fuente aportó 0.4 puntos a la reducción en el coeficiente de Gini.

Por su parte, en el período 2011-2015 no existieron modificaciones importantes en esta fuente de ingresos: el porcentaje de hogares beneficiándose del mismo se mantuvo relativamente constante en $12.4 \%$, su participación en el ingreso por adulto equivalente creció ligeramente (de $1.0 \%$ a $1.1 \%$ ) y su distribución no varió demasiado: el IC de esta fuente de ingresos mostró una leve mejoría entre 2011 (-0.402) y 2015 (-0.435). En este escenario, es esperable que la contribución a la mejora en la desigualdad de esta fuente de ingresos sea prácticamente nula en este período.

En resumen, a lo largo de los 12 años del período analizado se observó un crecimiento considerable en el porcentaje de hogares beneficiarios de transferencias estatales, desde $4.0 \%$ a $12.4 \%$. Como resultado de ello, la participación de esta fuente de ingresos en el ingreso por adulto equivalente casi que se duplicó, pasando de $0.6 \%$ a $1.1 \%$. Además, la expansión de las transferencias estatales se realizó con un buen nivel de focalización, por lo que se mejoró el impacto distributivo igualador de este tipo de transferencias: el IC de las transferencias estatales mejoró de -0.231 en 2003 a - 0.435 en 2015. Debido al accionar conjunto de estos factores, la evolución del ingreso por transferencias estatales tuvo un efecto igualador en 2003-2015, contribuyendo con 1 punto a la reducción del coeficiente de Gini en el período. 


\section{IV.4.3 La evolución de otros ingresos no laborales}

El ítem de "otros ingresos no laborales" incluye ingresos de distintas características, aunque los más importantes podrían clasificarse como ingresos de capital: alquiler de propiedades, ganancias de negocio en el que no trabajó e intereses de plazo fijo o rentas de inversiones. En el período analizado estos otros ingresos no laborales perdieron participación en el ingreso por adulto equivalente: de representar $6.3 \%$ del mismo en 2003, cayeron a $4.9 \%$ en 2007, a $4.3 \%$ en 2011 y a $4.0 \%$ en 2015 . La mayor parte de esa caída se explica por los ingresos de capital, que representaban $3.1 \%$ del ingreso por adulto equivalente en 2003 y se situaron en apenas $1.2 \%$ en 2015. Si bien es sabido que los ingresos de capital no son muy bien capturados en las encuestas de hogares, el caso de la EPH posiblemente obedezca a problemas derivados de la situación del INDEC entre 2007 y 2015 (falta de entrenamiento de entrevistadores para captar estos ingresos y/o falta de interés en colaborar de los entrevistados, por ejemplo). En ese sentido, es posible que la desigualdad en la EPH se encuentre subestimada debido a esos problemas.

Estos otros ingresos no laborales tenían una distribución muy desigual en 2003: el IC de este ingreso es significativamente mayor a los IC de las restantes fuentes, en todos los años (Tabla 5). Debido a ello, la disminución de la participación de esta fuente en el ingreso por adulto equivalente puede haber contribuido a la caída en la desigualdad, al igual que ciertas mejoras en su distribución que se observaron en 2003-2007 y, en menor medida, en 20112015. En este sentido, es de esperar que la mayor contribución de estos ingresos a la reducción en la desigualdad se haya dado en la primera etapa, 2003-2007, donde la participación de esta fuente se redujo significativamente (de $6.3 \%$ a $4.9 \%$ ) y donde la desigualdad en su distribución también cayó en una magnitud considerable (el IC pasó de 0.670 en 2003 a 0.508 en 2007). Esto se confirma en la Figura 4.2, que indica que en ese período la evolución de los otros ingresos no laborales contribuyó con 0.6 puntos a la caída en la desigualdad medida por el coeficiente de Gini del ingreso por adulto equivalente.

\section{IV.5 Demografía}

Los cambios demográficos pueden tener influencia sobre la dinámica de 
la distribución del ingreso familiar. Esta sección se focaliza en un factor demográfico particular: el cambio en los patrones de fecundidad. En el corto y mediano plazo el cambio en el número de hijos por familia puede afectar el ingreso equivalente del hogar mediante dos canales: alterando el número de adultos equivalentes, y afectando sus decisiones laborales ${ }^{18}$.

Para evaluar la relevancia de estos factores se sigue la metodología sugerida por Marchionni y Gasparini (2007). De forma similar a la simulación del cambio en la estructura educativa, el cambio en la cantidad de hijos por hogar se hace por grupos. Estos grupos están formados por la combinación de quintiles de ingreso del jefe y cónyuge y la edad del jefe del hogar ${ }^{19}$. Se calcula la cantidad de hijos que en promedio tiene un grupo determinado en $t^{\prime}$ y se lo reemplaza en $t$, para determinar a continuación las horas trabajadas de los ocupados del período base, con la nueva estructura de hijos.

La Tabla 6 muestra los resultados de las descomposiciones. A lo largo del período el efecto fecundidad ha contribuido a la reducción de la desigualdad, dado un patrón más marcado de reducción del número de hijos en los hogares más pobres y un mayor efecto de ese cambio en las decisiones laborales. De cualquier forma, el impacto igualador de los cambios en los patrones de fecundidad sobre la distribución del ingreso equivalente ha sido menor: apenas 0.33 puntos sobre una caída total de 11.8 puntos entre 2003 y 2015.

\section{Discusión}

Este trabajo caracteriza los cambios en la pobreza y la indigencia en Argentina entre los años 2003 y 2015 a partir de un conjunto de descomposiciones, enfatizando la conveniencia de dividir el período en tres etapas con dinámicas económicas muy diferentes, que se reflejan en resultados sociales distintos: 2003-2007, 2007-2011 y 2011-2015.

La primera etapa abarca desde 2003 a 2007 y está marcada por la fuerte expansión económica que se produjo a la salida de la profunda crisis

\footnotetext{
${ }^{18}$ En el largo plazo las implicancias pueden ser más complejas. Por ejemplo, al crecer los hijos pueden contribuir al presupuesto familiar, aun cuando dejen el hogar. Naturalmente, los cambios en la estructura demográfica también tienen efectos de equilibrio general en el largo plazo.

${ }^{19}$ Para la formación de grupos, se tuvieron en cuenta tres divisiones de edad del jefe de hogar $([15-25),[25,45)$ y $[45,+))$ junto con 5 quintiles de ingreso del jefe y cónyuge, formando 15 grupos en total.
} 
Tabla 6: Descomposición de los cambios en el coeficiente de Gini. Efecto del cambio en el número de hijos

\begin{tabular}{lcccc}
\hline \hline & $2003-2007$ & $2007-2011$ & $2011-2015$ & $2003-2015$ \\
\hline Cambio observado & -6.5 & -3.6 & -1.7 & -11.8 \\
\hline Efecto fecundidad & -0.16 & 0.08 & -0.24 & -0.33 \\
\hline
\end{tabular}

Nota: Descomposición de Bourguignon et al. (2005) del coeficiente de Gini, calculado en base al ingreso por adulto equivalente sobre la línea de pobreza. Los cambios en el Gini están multiplicados por 100.

macroeconómica de 2001/02, con salarios reales inicialmente deprimidos luego de la devaluación y en un contexto internacional muy favorable. En ese escenario, el mercado laboral se mostró dinámico, lo que contribuyó a las mejoras que experimentaron todos los indicadores sociales en ese período de rebote económico. En particular, tanto la tasa de pobreza (de $58.2 \%$ a $37.6 \%$ ) como la tasa de indigencia $(21.1 \%$ a $9.0 \%)$ se redujeron significativamente, bajando a niveles similares a los que tenían pre-crisis. En estos años el principal factor detrás de la caída en los indicadores de privaciones de ingreso fue el crecimiento económico, que da cuenta del $72 \%$ de la baja en la tasa de pobreza. La contribución de la reducción en la desigualdad fue relativamente menor pero no insignificante (28\%). Gran parte de esta caída en la desigualdad está vinculada a cambios en el ingreso laboral, que es la principal fuente de ingreso de la mayor parte de los hogares. En particular, el aumento generalizado de los salarios horarios reales y la recomposición del empleo, especialmente entre los no calificados, jugaron un papel importante en reducir la desigualdad. Por su parte, tanto la evolución de los ingresos por jubilaciones y pensiones (como consecuencia de la moratoria previsional que comenzó a finales de 2005), como de los ingresos por transferencias estatales (producto del PJJHD, el FIS y otros programas aplicados por el Ministerio de Desarrollo Social) aportaron a la reducción de la desigualdad, aunque la magnitud de esa contribución sea pequeña relativamente a la que tuvo la evolución de los ingresos laborales.

La segunda etapa, que cubre el período 2007-2011, tuvo una dinámica diferente. Con el efecto rebote post-crisis agotado y con condiciones externas buenas pero no extraordinarias, la economía argentina continuó creciendo, pero 
a tasas menores y con oscilaciones más fuertes. En este contexto, la pobreza de ingresos continuó bajando, aunque a un ritmo menor al del período anterior (de $37.6 \%$ a $29.4 \%$ ). La tracción del crecimiento sobre la caída en la pobreza entre 2007 y 2011 fue menor que en la etapa previa: las descomposiciones indican que su contribución a la caída de la pobreza fue algo menor al $50 \%$ y su aporte a la caída de la indigencia fue nulo. Aunque la reducción en la desigualdad tuvo un papel relativamente más importante en la reducción de la indigencia y la pobreza en esta etapa que en la previa, en términos absolutos la caída de la desigualdad también mostró una desaceleración en esta etapa. El mayor aporte a la reducción de la desigualdad provino de los ingresos laborales. A diferencia del período anterior ni la recomposición del salario ni del empleo jugaron un papel relevante; en su lugar la evidencia sugiere un efecto igualador de la compresión salarial asociada a una reducción de la brecha por educación. Por su parte, la evolución de los ingresos por jubilaciones y pensiones, producto de la moratoria implementada entre 2005 y 2008, y de los ingresos por transferencias estatales, como consecuencia de la implementación de la AUH a finales de 2009, fueron factores que contribuyeron significativamente a la reducción de la desigualdad y la pobreza en esta etapa.

La tercera y última etapa, que abarca los años de 2011 a 2015, es un período caracterizado por el estancamiento económico y social. Los desbalances acumulados en años anteriores, las inconsistencias macroeconómicas y un contexto internacional no tan favorable se conjugaron para frenar la economía argentina. En ese contexto las mejoras sociales se estancaron: la tasa de pobreza aumentó ligeramente $(29.4 \%$ a $30.1 \%)$, mientras que otros indicadores de pobreza e indigencia se redujeron solo marginalmente. Esta situación se alcanzó por la combinación de una leve retracción en el ingreso por adulto equivalente entre 2011 y 2015 con una mejora marginal en la distribución del ingreso. La desaceleración de la caída en la desigualdad se entiende a partir del estancamiento de los factores que traccionaron estos cambios en las etapas anteriores. Entre 2011 y 2015 no hubo avances en términos de salario real o empleo, ni reducción significativa de brechas salariales, ni expansión de la política social de transferencias monetarias. 


\section{Referencias}

Alejo, J., Parada, C. y Gasparini, L. (2018). "Distributive implications of changing female employment: Latin America, 1990-2012". Manuscrito no publicado, Universidad Nacional de la Plata.

Altimir, O., Beccaria, L. y González Rozada, M. (2002). "La distribución del ingreso en Argentina, 1974-2000”. Revista de la CEPAL.

Azevedo, J.P., Nguyen, M.C., y Sanfelice, V. (2012). "ADECOMP: Stata module to estimate Shapley Decomposition by Components of a Welfare Measure". Statistical Software Components.

Azevedo, J. P., Inchauste, G., Olivieri, S., Saavedra, J., \& Winkler, H. (2013). "Is labor income responsible for poverty reduction? A decomposition approach". The World Bank.

Barros, R.P.D., Carvalho, M.D., Franco, S., y Mendonça, R. (2006). "Uma análise das principais causas da queda recente na desigualdade de renda brasileira". Econômica, V.8, N.1, p. 117-147, Universidade Federal Fluminense.

Beccaria, L., R. Maurizio, A. Fernández, P. Monsalvo \& M. Alvarez (2010) "Dynamics of poverty, labor market and public policies in Latin America", PMMA Working Paper 2010-09, Poverty and Economic Policy Research Network.

Beccaria, L., Maurizio, R., y Vazquez, G. (2014). "Recent changes in wage inequality in Argentina. The role of labor formalization and other factors".

Bertranou, F., y Maurizio, R. (2011). "The role of labour market and social protection in reducing inequality and eradicating poverty in Latin America". Available at SSRN 1857705.

Bourguignon, F., Ferreira, F.H., y Lustig, N. (2005). "The microeconomics of income distribution dynamics in East Asia and Latin America". New York: Oxford University Press.

Bustelo, M., y Lucchetti, L. (2004). "La pobreza en Argentina: perfil, evolución y determinantes profundos (1996, 1998 y 2001)". Documentos de Trabajo del CEDLAS. 
César, A. (2016). "Explorando la dinámica distributiva Argentina en los años que siguen a la crisis de 2001-2002”. Asociación Argentina de Economía Política. Disponible en los Anales 2016-Tucuman: https://aaep.org.ar/anales/works/works2016/cesar.pdf

Datt, G. y Ravallion, M. (1992). "Growth and redistribution components of changes in poverty measures: A decomposition with applications to Brazil and India in the 1980s". Journal of Development Economics 382, 275-295.

Deaton, A. (1997). "The analysis of household surveys: a microeconometric approach to development policy". The World Bank.

Dinardo, J., Fortin, N. M. y Lemiux, T. (1996). "Labour market institutions and the distribution of wages, 1973-1992: a semi-parametric approach", Econometrica 64(5), pp. 100-44.

Firpo, S., Fortin, N. M., y Lemieux, T. (2009). "Unconditional quantile regressions", Econometrica, 77(3), 953-973.

Fortin, N., Lemieux, T. y Firpo, S. (2011). "Decomposition Methods in Economics". In the Handbook of Labor Economics.

Gasparini, L., Cicowiez, M. y Sosa Escudero, W. (2013) "Pobreza y Desigualdad en América Latina: Conceptos, herramientas y aplicaciones". Buenos Aires. Editorial Temas.

Gasparini, L. y Cruces, G. (2009) "Desigualdad en Argentina. Una revisión de la evidencia empírica: Primera Parte”, Desarrollo economico, 395-437.

Gasparini, L., Marchionni, M. y Sosa Escudero, W. (2005). "Characterization of inequality changes through microeconometric decomposition. The case of Great Buenos Aires". In "The Microeconomics of Income Distribution Dynamics in East Asia and Latin America", eds Bourguignon, F., F. Ferreira y N. Lustig. New York: Oxford University Press.

Inchauste, G., Azevedo, J.P., Essama-Nssah, B., Olivieri, S., Van Nguyen, T., Saavedra-Chanduvi, J., y Winkler, H. (2014). "Understanding changes in poverty". World Bank Publications.

INDEC. (2016). "Revisión del Producto Interno Bruto, base 2004 y series de Oferta y Demanda Globales". 
Juhn, C., Murphy, K. M., y Pierce, B. (1993). "Wage inequality and the rise in returns to skill," Journal of political Economy 101(3), 410-442.

Lustig, N. y Lopez-Calva, L. (2009). "The recent decline of inequality in Latin America: Argentina, Brazil, Mexico and Peru".

Machado, J. A., y Mata, J. (2005). "Counterfactual decomposition of changes in wage distributions using quantile regression." Journal of applied Econometrics 20(4), 445-465.

Marchionni, M., y Gasparini, L. (2007). "Tracing out the effects of demographic changes on the income distribution", The Journal of Economic Inequality 5(1), 97-114.

Parada, C. (2014). "Empleo femenino, pobreza y desigualdad. Un análisis de microdescomposiciones. Uruguay 1991-2012”. Documento de Trabajo 174, CEDLAS.

Sanz, G. (2019). "Estimación de ingresos en base a múltiples fuentes”. Mimeo.

Sen, A. (1976). "Poverty: an ordinal approach to measurement", Econometrica: Journal of the Econometric Society, 219-231.

Trujillo, L. y S. Villafañe. (2011). "Dinámica Distributiva y Políticas Públicas: Dos Décadas de Contrastes en la Argentina Contemporánea", in Novick, M. and S. Villafañe (eds) Distribución del Ingreso. Enfoques y políticas públicas desde el sur, MTESS - UNDP, Buenos Aires.

Tornarolli, L. (2018). "Series Comparables de Indigencia y Pobreza: Una Propuesta Metodológica". Documento de Trabajo 226, CEDLAS.

Tsakloglou, P. (1993). "Aspects of inequality in Greece: Measurement, decomposition and intertemporal change: 1974, 1982". Journal of Development Economics 40(1), 53-74.

Zoloa, J. (2011). "Los cambios en la distribución del ingreso de Argentina entre 1998 y 2005”. Documentos de Trabajo del CEDLAS. 


\section{A. Apéndice: Metodologías de Microdescomposición}

\section{A.1 Crecimiento y distribución}

Una manera sencilla de implementar en la práctica una descomposición que nos ilustre las magnitudes relativas de los efectos crecimiento y redistribución consiste en expresar la pobreza como el resultado de la interacción de una línea de pobreza $\mathbf{z}$, el ingreso medio $\mu$ y la forma de la distribución, captada por su curva de Lorenz, $\mathbf{L}(\mathbf{p})$ :

$$
P=P(\mu, L(p), z)
$$

Denotando con $\Delta \mathbf{P}$ al cambio en la pobreza entre los momentos $\mathbf{t}_{\mathbf{1}} \mathrm{y}_{\mathbf{2}} \mathrm{y}$ asumiendo que la línea de pobreza $\mathbf{z}$ no cambia, es posible escribir:

$$
\Delta P=P\left(\mu_{2}, L_{2}(p), z\right)-P\left(\mu_{1}, L_{1}(p), z\right)
$$

Si se suma y se resta a ambos términos $P\left(\mu_{1}, L_{2}(p), z\right)$, se obtiene que:

$$
\begin{aligned}
\Delta P= & {\left[P\left(\mu_{2}, L_{2}(p), z\right)-P\left(\mu_{1}, L_{2}(p), z\right)\right]+} \\
& +\left[P\left(\mu_{1}, L_{2}(p), z\right)-P\left(\mu_{1}, L_{1}(p), z\right)\right]
\end{aligned}
$$

La ecuación A.1.3 muestra cómo cambios en la pobreza resultan de la suma de dos posibles cambios: el generado por una modificación en el ingreso medio, con la forma de la distribución constante (primer término, que capta el efecto crecimiento) y aquel generado por una modificación de la curva de Lorenz, ante un ingreso medio fijo (segundo término, que captura el efecto redistribución).

En la práctica, los términos $\mathbf{P}\left(\mu_{\mathbf{t}}, \mathbf{L}_{\mathbf{t}}(\mathbf{p}), \mathbf{z}\right)$ son simplemente la pobreza efectiva estimada en $t$. El término $\mathbf{P}\left(\mu_{1}, \mathbf{L}_{2}(\mathbf{p}), \mathbf{z}\right)$ se calcula tomando la distribución en $\mathbf{t}_{2}$ y multiplicando todos los ingresos por $\mu_{1} / \mu_{2}$.

Este mismo ejercicio se podría realizar alterando los años base, de manera que el cambio en la pobreza también podría escribirse como:

$$
\begin{aligned}
\Delta P= & {\left[P\left(\mu_{2}, L_{1}(p), z\right)-P\left(\mu_{1}, L_{1}(p), z\right)\right]+} \\
& +\left[P\left(\mu_{2}, L_{2}(p), z\right)-P\left(\mu_{2}, L_{1}(p), z\right)\right]
\end{aligned}
$$

Un procedimiento usual es tomar el promedio de estas opciones para calcular ambos efectos, escribiendo el cambio en la pobreza debido al efecto crecimiento como: 


$$
\begin{aligned}
\Delta P_{C}= & \frac{1}{2}\left[P\left(\mu_{2}, L_{1}(p), z\right)-P\left(\mu_{1}, L_{1}(p), z\right)\right]+ \\
& +\frac{1}{2}\left[P\left(\mu_{2}, L_{2}(p), z\right)-P\left(\mu_{1}, L_{2}(p), z\right)\right]
\end{aligned}
$$

y el correspondiente al efecto redistribución como:

$$
\begin{aligned}
\Delta P_{R}= & \frac{1}{2}\left[P\left(\mu_{1}, L_{2}(p), z\right)-P\left(\mu_{1}, L_{1}(p), z\right)\right]+ \\
& +\frac{1}{2}\left[P\left(\mu_{2}, L_{2}(p), z\right)-P\left(\mu_{2}, L_{1}(p), z\right)\right]
\end{aligned}
$$

Es posible expresar entonces el cambio en la pobreza en dos términos: el efecto crecimiento $\Delta \mathbf{P}_{\mathbf{C}}$ y el efecto redistribución $\Delta \mathbf{P}_{\mathbf{R}}$ :

$$
\Delta P=\Delta P_{C}+\Delta P_{R}
$$

La metodología expuesta es una variante de la inicialmente propuesta por Datt y Ravallion (1992). En su forma original, esta descomposición incluye un término residual y el valor de los efectos depende del período elegido como base o referencia. Para resolver este problema la práctica estándar es calcular la descomposición en ambos sentidos y luego tomar el promedio (Gasparini et al., 2013, Inchauste et al., 2014), como se detalló en las ecuaciones A.1.5 y A.1.6.

\section{A.2 Descomposición por fuentes de ingreso}

Para la descomposición de la sección 4.2 se ha seguido la metodología propuesta por Azevedo et al. (2012), que extiende la descomposición desarrollada por Barros, Carvalho, Franco y Mendonça (2006).

$\mathrm{El}$ ingreso por adulto equivalente $\left(y_{\mathrm{ae}}^{h}\right)$ es la medida de bienestar utilizada en Argentina en las estimaciones de pobreza y en este trabajo en la estimación de desigualdad. Se define como la suma de los ingresos individuales $\left(\mathbf{y}_{\text {ih }}\right)$ de los $\mathbf{n}$ miembros del hogar $\mathbf{h}$, dividido la cantidad de adultos equivalentes en el hogar $\left(\mathrm{ae}_{\mathrm{h}}\right)$ :

$$
y_{a e}^{h}=\frac{1}{a e_{h}} \sum_{i=1}^{n} y_{i h}=\frac{n}{a e_{h}} y_{p c}^{h}
$$

Donde $\mathbf{y}_{\mathrm{pc}}^{\mathbf{h}}$ es el ingreso per cápita familiar del hogar $\mathbf{h}$. Si desagregamos los ingresos individuales en ingresos laborales $\mathbf{y}_{\mathrm{ih}}^{\mathrm{L}}$ y no laborales $\mathbf{y}_{\mathrm{ih}}^{\mathrm{NL}}$, la ecuación A.2.1 puede reescribirse como: 


$$
y_{a e}^{h}=\frac{1}{a e_{h}}\left(\sum_{i=1}^{n} y_{i h}^{L}+\sum_{i=1}^{n} y_{i h}^{N L}\right)=\frac{n}{a e_{h}} y_{p c}^{L_{h}}+\frac{n}{a e_{h}} y_{p c}^{N L_{h}}
$$

Donde $\mathbf{y}_{\mathrm{pc}}^{\mathbf{L}_{\mathbf{h}}}$ e $\mathbf{y}_{\mathrm{pc}}^{\mathrm{NL}_{\mathbf{h}}}$ son, respectivamente, el ingreso laboral per cápita familiar y el ingreso no laboral per cápita familiar del hogar $\mathbf{h}$. Si definimos el ingreso laboral por adulto equivalente $\left(\mathbf{y}_{\mathrm{ae}}^{\mathbf{L}_{\mathrm{h}}}\right)$ y el ingreso no laboral por adulto equivalente $\left(\mathrm{y}_{\mathrm{ae}}^{\mathrm{NL}_{\mathbf{h}}}\right)$ como:

$$
\begin{aligned}
y_{a e}^{L_{h}} & =\frac{n}{a e_{h}} y_{p c}^{L_{h}} \\
y_{a e}^{N L_{h}} & =\frac{n}{a e_{h}} y_{p c}^{N L_{h}}
\end{aligned}
$$

Entonces, la ecuación A.2.2 puede reescribirse como:

$$
y_{a e}^{h}=y_{a e}^{L_{h}}+y_{a e}^{N L_{h}}
$$

En el ejercicio de la sección 4.2, el ingreso por adulto equivalente está definido como la suma de los ingresos por adulto equivalente en concepto de ingreso laboral e ingresos no laborales en las siguientes categorías: ingresos por jubilaciones, ingresos por transferencias estatales y otros ingresos no laborales. De este modo, se puede reescribir A.2.5 como:

$$
y_{a e}^{h}=y_{a e}^{L_{h}}+y_{a e}^{\text {jubi }_{h}}+y_{a e}^{\text {transfe }_{h}}+y_{a e}^{\text {otros }_{h}}
$$

Entonces, siendo $\vartheta$ cualquier indicador de desigualdad, el mismo dependerá del ingreso por adulto equivalente y con éste, de todas las fuentes de ingreso en las que se desagregó el mismo. Más formalmente, el indicador de desigualdad será función de la función de distribución acumulada $\mathbf{F}($.$) del ingreso por adulto$ equivalente, que a la vez depende de las distintas fuentes de ingreso consideradas en su definición:

$$
\vartheta=\varphi\left(F\left(y_{a e}\left(y_{a e}^{L_{h}}, y_{a e}^{\text {jubi }_{h}}, y_{a e}^{\text {transfe }_{h}}, y_{a e}^{\text {otros }_{h}}\right)\right)\right)
$$

Dado que las distribuciones del ingreso por adulto equivalente para los períodos $\mathbf{t}_{1}$ y $\mathbf{t}_{2}$ se pueden observar, este método de descomposición del cambio 
en la desigualdad consiste en generar nuevas distribuciones contrafácticas sustituyendo el valor observado de los determinantes en la ecuación A.2.7 en $\mathbf{t}_{\mathbf{1}}$ por su correspondiente valor en $\mathbf{t}_{\mathbf{2}}$, de a uno por vez. Para cada distribución contrafáctica obtenida, es posible calcular un índice de desigualdad, que es el que hubiese prevalecido si un determinante hubiese tomado el valor del otro período.

El impacto del cambio en cada componente se calcula como la diferencia entre los contrafácticos acumulados para un posible sendero de cambio. Por ejemplo, el resultado de cambiar el promedio de los ingresos laborales por adulto equivalente en $\mathbf{t}_{\mathbf{1}}$ por el valor correspondiente al de $\mathbf{t}_{\mathbf{2}}$ es una distribución contrafáctica con la que se calculará un coeficiente de Gini. La diferencia entre este coeficiente y el calculado en base a la distribución real será el efecto del cambio en el ingreso laboral por adulto equivalente en la desigualdad. Luego, al cambio en el ingreso laboral se le suma el cambio en el ingreso por jubilaciones por adulto equivalente, obteniendo una nueva distribución contrafáctica. La diferencia entre el coeficiente de Gini que resulte de esta nueva distribución contrafáctica y el coeficiente obtenido con la distribución contrafáctica resultante de la sustitución anterior será la contribución del cambio en el ingreso por jubilaciones al cambio en la desigualdad. El ejercicio se realiza para todos los componentes de la ecuación A.2.7, obteniendo así los efectos marginales de cada uno de ellos.

Este mismo ejemplo se podría haber dado sustituyendo primero los ingresos por adulto equivalente por transferencias o por jubilaciones, por lo que los efectos marginales asociados a cada fuente de ingreso podrían ser distintos de acuerdo al sendero que se elija, lo que es conocido como el problema de path dependence. Azevedo et al. (2012) resuelven este problema aplicando el método de Shapley-Shorrocks, que consiste en realizar el ejercicio para todos los posibles senderos de cambio y promediar el efecto que tiene cada fuente en cada uno de ellos. Este método implica 24 (=4!) senderos de cambio posibles (dado que el ingreso por adulto equivalente se desagregó en 4 fuentes de ingresos), por lo que el resultado que se obtiene surge de promediar los efectos de cada componente en las 24 simulaciones.

\section{A.3 Descomposición de ingresos laborales}

Esta descomposición sigue la metodología propuesta originalmente por 
Bourguignon et al. (2005), aplicada por Gasparini et al. (2005) en el caso Argentino para analizar desigualdad en Gran Buenos Aires.

El ingreso total del individuo $i$ en el momento $t$ puede escribirse como la suma de sus ingresos laborales $\mathbf{y}_{\text {it }}^{\mathrm{L}}$ y sus ingresos no laborales $\mathbf{y}_{\mathrm{it}}^{\mathrm{NL}}$ :

$$
y_{i t}=y_{i t}^{L}+y_{i t}^{N L}
$$

Mientras los ingresos no laborales son considerados exógenos en este ejercicio, los ingresos laborales surgen del producto del salario horario $\mathbf{w}_{\text {it }} \mathrm{y}$ de la cantidad de horas trabajadas $\mathbf{L}_{\mathrm{it}}$ :

$$
y_{i t}^{L}=w_{i t} * L_{i t}
$$

La ecuación A3.2 depende a su vez de características observables $\mathbf{X}_{\text {it }}$ que afectan tanto el salario como el empleo, de características inobservables $\varepsilon_{\mathrm{it}} \mathrm{y}$ de un vector de parámetros $\beta_{\mathbf{t}}$ (que afecta la determinación del salario horario) y otro vector $\lambda_{\mathbf{t}}$ (que afecta la determinación de las horas trabajadas):

$$
y_{i t}^{L}=F\left(X_{i t}, \epsilon_{i t}, \beta_{t}, \lambda_{t}\right)
$$

La ecuación A3.3 define los determinantes del ingreso laboral del individuo i en el momento t. Sin embargo, es más relevante desde un punto de vista social analizar la distribución del ingreso familiar, dado que la utilidad de una persona depende no solo de los ingresos propios sino del ingreso del hogar y de la composición demográfica. El ingreso por adulto equivalente se define como:

$$
y_{a e}^{h}=\frac{1}{a e_{h}} \sum_{i \in h}\left(F\left(X_{i t}, \epsilon_{i t}, \beta_{t}, \lambda_{t}\right)+y_{i t}^{N L}\right) \quad \forall i \in h
$$

donde $\mathrm{ae}_{\mathbf{h}}$ denota el número de adultos equivalentes del hogar $\mathbf{h}$.

Sea $\mathbf{k}$ un parámetro cualquiera de la ecuación A3.3. Es posible simular el ingreso laboral que el individuo $\mathbf{i}$ hubiese obtenido en el momento $\mathbf{t}_{2}$, al sustituir el valor de $\mathrm{k}$ por el correspondiente en $\mathbf{t}_{2}$, manteniendo el resto de los determinantes constantes. Dado que reemplazar los parámetros de $\mathbf{t}_{2}$ en los datos de $\mathbf{t}_{\mathbf{1}}$ arroja resultados diferentes al hacerlo invirtiendo el orden, se calculan las distribuciones contrafácticas de una y otra forma y se computa el promedio de ambas. De este modo, puede obtenerse una distribución del ingreso por adulto equivalente observada, $\mathbf{D}_{\mathbf{t}}$ : 


$$
D_{t}=\left(y_{1 t}, \ldots, y_{N t}\right)
$$

y una simulada, $\mathbf{D}_{\mathrm{tk}}$ :

$$
D_{t k}=\left(y_{1 t}\left(k_{t^{\prime}}\right), \ldots, y_{N t}\left(k_{t^{\prime}}\right)\right)
$$

El impacto marginal del cambio en el parámetro $\mathbf{k}$ surge de comparar un indicador distributivo $\mathbf{I}(\mathbf{D})$ calculado sobre la distribución observada y la simulada:

$$
I\left(D_{t k}\right)-I\left(D_{t}\right)
$$

Para simular los ingresos laborales, se estima una ecuación de forma reducida para los salarios horarios $\mathbf{w}_{\mathrm{it}} \mathrm{y}$ una para la cantidad de horas trabajadas $\mathbf{L}_{\mathrm{it}}$ :

$$
\begin{aligned}
& w_{i t}^{*}=X_{i t}^{w} \beta_{t}+\epsilon_{i t}^{w} \\
& L_{i t}^{*}=X_{i t}^{L} \lambda_{t}+\epsilon_{i t}^{L}
\end{aligned}
$$

$\operatorname{con}\left(\varepsilon_{\mathrm{it}}^{\mathbf{w}}, \varepsilon_{\mathrm{it}}^{\mathbf{L}}\right) \sim \mathbf{N}\left(\mathbf{0}, \mathbf{0}, \sigma_{\mathbf{w}}, \sigma_{\mathbf{L}}, \rho\right)$. Además, se asume que:

$$
\begin{aligned}
& w_{i t}=w_{i t}^{*} \quad \text { si } \quad L_{i t}^{*} \quad>0 \\
& w_{i t}=0 \quad \text { si } \quad L *_{i t} \leq 0 \\
& L_{i t}=L_{i t}^{*} \quad \text { si } \quad L_{i t}^{*} \quad>0 \\
& L_{i t}=0 \quad \text { si } L *_{i t} \leq 0
\end{aligned}
$$

donde $\mathbf{w}_{\text {it }}$ y $\mathbf{L}_{\text {it }}$ representan el salario horario y las horas trabajadas del individuo $\mathbf{i}$ en el momento $\mathbf{t}$ que se observa en los datos. Por su parte, $\mathbf{w}_{\mathrm{it}}^{*} \mathrm{y}$ $\mathbf{L}_{\mathrm{it}}^{*}$ son variables latentes, dado que los salarios y las horas trabajadas sólo se observan para aquellas personas que participan en el mercado laboral. Los vectores $\mathbf{X}_{\mathrm{it}}^{\mathrm{w}}$ y $\mathbf{X}_{\mathrm{it}}^{\mathrm{L}}$ contienen características observables de los trabajadores que afectan al salario horario y a las horas trabajadas, respectivamente. De forma similar, los vectores $\beta_{\mathbf{t}}$ y $\lambda_{\mathbf{t}}$ contienen los coeficientes respectivos de cada característica en $\mathbf{X}_{\mathrm{it}}^{\mathbf{w}}$ y $\mathbf{X}_{\mathrm{it}}^{\mathbf{L}}$. Además, ambas ecuaciones están afectadas por una serie de factores inobservables $\varepsilon_{\mathrm{it}}^{\mathrm{w}}$ y $\varepsilon_{\mathrm{it}}^{\mathbf{L}}$. 
Dado que los coeficientes estimados de la ecuación A3.8 sufren de sesgo de selección debido a que sólo se observa el retorno a las características de personas que trabajan, los salarios horarios se estiman mediante el método de Heckman en dos etapas. La ecuación de horas trabajadas, por otra parte, se estima mediante un modelo Tobit de datos censurados.

Los ingresos laborales que se simulan con el cambio de cada determinante $\mathbf{k}$ se calculan sobre una muestra conformada por personas de entre 15 y 65 años. Los restantes ingresos del hogar (ingresos de capital, de transferencias, entre otros) se mantienen inalterados, al igual que los ingresos de los trabajadores de la muestra que no cumplen con la condición etaria. Por último, siguiendo a Gasparini et al. (2005), dado que las estimaciones de las ecuaciones A3.8 y A3.9 pueden diferir de acuerdo con el rol del trabajador en el hogar, las estimaciones de los parámetros distinguen jefes, cónyuges y otros miembros del hogar.

Para caracterizar los cambios en la desigualdad en la sección 4.3 se realizan 7 simulaciones ${ }^{20}$. Las tres primeras consisten en evaluar qué hubiese sucedido con la desigualdad en $\mathbf{t}_{1}$ sí determinados parámetros de la ecuación de salarios hubiesen sido los del momento $\mathbf{t}_{\mathbf{2}}$. En particular se consideran por separado cambios en la constante, en los coeficientes de las dummies educativas y en el coeficiente de la dummy de género (hombre). El cambio en la constante capta cambios generalizados en el salario real, el cambio en los coeficientes de las dummies educativas captura cambios en los retornos a la educación, mientras que variaciones en el coeficiente de la dummy de hombre captan cambios en la brecha condicional de género.

El cuarto ejercicio de simulación está destinado a medir el impacto de cambios en la dispersión de los factores inobservables que afectan el salario. Estos factores son modelados como los errores de la regresión A3.8 $\left(\mathbf{k}=\varepsilon_{\mathrm{it}}^{\mathbf{w}}\right)$. Con el objetivo de simular el efecto de cambios en estos factores inobservables entre $\mathbf{t}_{1}$ y $\mathbf{t}_{\mathbf{2}}$ en la desigualdad los residuos del año $\mathbf{t}_{\mathbf{1}}$ son reescalados por el ratio $\frac{\sigma_{\mathbf{t}^{\prime}}}{\sigma_{\mathrm{t}}}$, donde $\sigma$ es el desvío estándar estimado en la ecuación de salarios.

Para evaluar la relevancia de los cambios en el empleo sobre la desigualdad, se realizan dos simulaciones, que implican la sustitución del vector de coeficientes estimados de la ecuación Tobit de horas trabajadas $(\mathbf{k}=\lambda)$. En la simulación de las horas trabajadas, se sustituye el vector de coeficientes $\lambda$ en $\mathbf{t}_{\mathbf{1}}$ por el de $\mathbf{t}_{2}$ para todas aquellas personas que trabajan, manteniendo los salarios

${ }^{20}$ Las simulaciones se realizan de a una por vez, ceteris paribus. 
base. En esta simulación no hay posibilidad de cambios en la situación laboral, por lo que aquellas personas con horas trabajadas iguales a cero no pueden incorporarse al mercado laboral, mientras que aquellas que sí trabajaban en el escenario base no pueden dejar de hacerlo en el simulado.

La segunda simulación, denominada efecto "empleo", está destinada a aislar solo el impacto de cambios en el status laboral entre empleado y no empleado o viceversa, ignorando cambios en las demás variables laborales (horas trabajadas o salarios). La simulación implica exportar los coeficientes $\lambda$ de un año a otro y focalizarse en aquellas personas que cambian su status laboral producto de este ejercicio. Para algunas personas la simulación implica el paso del empleo al noempleo: es indistinto en este caso si pasan a ser desempleadas o inactivas, ya que en ambos casos su ingreso es nulo, y por lo tanto es idéntico su efecto sobre la distribución del ingreso. Es más interesante el caso de aquellas personas que en la simulación pasan a ser empleadas. Estas personas necesitan salarios y horas simuladas que resultarán del producto de sus características con los coeficientes estimados (los $\lambda$ de $\mathbf{t}_{2}$ y los $\beta$ de $\mathbf{t}_{1}$ ). Para estas personas, resta definir qué errores les corresponden para las ecuaciones A3.8 y A3.9, errores que deben ser consistentes con las decisiones de no trabajar en el escenario base. Es decir, para cada nuevo trabajador los errores $\varepsilon_{\mathrm{it}}^{w}$ y $\varepsilon_{\mathrm{it}}^{l}$ que serán parte de las ecuaciones A3.8 y A3.9 en el escenario simulado, deben generar un valor de horas trabajadas no positivo en el escenario base porque justamente, esas personas no trabajaban hasta antes del traslado de coeficientes. Una posibilidad es utilizar los parámetros estimados $\left(\widehat{\sigma_{\mathbf{W}}}, \widehat{\sigma_{\mathbf{L}}}, \widehat{\rho}\right)$ para generar aleatoriamente pares de errores a partir de un muestreo de una distribución normal bivariada, implícita en el modelo de Heckman. En el caso de que los residuos así generados no resultaran consistentes con la decisión original de no trabajar, se realizaría nuevamente el muestreo de errores para ese individuo, hasta que fuese coherente con su comportamiento observado (Gasparini et al., 2005; Parada, 2014). La alternativa que se sigue en este trabajo, emula el trabajo de Alejo, Parada y Gasparini (2018). Los autores proponen, dado el costo computacional de la opción anterior, usar el método de muestreo de la transformación inversa, compatible con los supuestos estadísticos de generación de datos del modelo econométrico. De este modo, puede obtenerse un par de errores $\varepsilon_{\mathrm{it}}^{\mathbf{W}}$ y $\varepsilon_{\mathrm{it}}^{\mathbf{L}}$ consistentes con la decisión de no trabajar, sin la necesidad de tener que iterar varias veces hasta conseguirlo.

Finalmente, la última simulación corresponde a cambios en la distribución 
de una característica clave de los individuos: su nivel educativo $\left(\mathrm{k}=\mathrm{X}^{\mathrm{edu}}\right)$. Con este objetivo se simulan los salarios y las horas trabajadas para los trabajadores de $\mathbf{t}_{1}$, si la estructura educativa fuera la correspondiente a $\mathbf{t}_{\mathbf{2}}$ pero los parámetros $\beta, \lambda$ y los errores, $\varepsilon_{\mathrm{it}}^{\mathbf{w}}$ y $\varepsilon_{\mathrm{it}}^{\mathbf{L}}$ se mantuviesen constantes. El cambio en la estructura educativa se implementa de la siguiente forma: se definen 12 grupos resultantes de la combinación de 6 grupos etarios y el género del trabajador ${ }^{21}$. Luego para cada grupo se calcula en la muestra el porcentaje de trabajadores entre 15 y 65 años que tienen determinado nivel educativo en $\mathbf{t}_{2}$, para luego reemplazarlo en $\mathbf{t}_{1}$. Así, si en $t_{2}$ el porcentaje de trabajadores con primaria incompleta en el grupo 1 es igual a $\theta$, en la simulación se imputará de manera aleatoria dentro de cada grupo la educación de los trabajadores de manera tal de replicar ese porcentaje. Este procedimiento se realiza teniendo en cuenta 6 dummies que reflejan el máximo nivel educativo del trabajador, incluidas en las ecuaciones del modelo: primaria incompleta, primaria completa, secundaria incompleta, secundaria completa, superior incompleta y superior completa ${ }^{22}$.

\section{A.4 Tablas}

\footnotetext{
${ }^{21}$ Los 6 grupos etarios de este procedimiento son 1: [15;18], 2: [19;29], 3: [30;39], 4: [40;49], 5: [50;59] y 6: [60;65]

${ }^{22}$ En el análisis de regresión la categoría primaria incompleta es la categoría base.
} 
Tabla A.1: Ecuación del logaritmo del salario horario.

\begin{tabular}{|c|c|c|c|c|c|c|c|c|c|c|c|c|}
\hline \multirow{2}{*}{$\begin{array}{l}\text { Log salario horario } \\
\text { Ecuación de salarios }\end{array}$} & \multicolumn{4}{|c|}{ Jefes } & \multicolumn{4}{|c|}{ Conyuges } & \multicolumn{4}{|c|}{ Otros } \\
\hline & 2003 & 2007 & 2011 & 2015 & 2003 & 2007 & 2011 & 2015 & 2003 & 2007 & 2011 & 2015 \\
\hline primaria completa & $0.129^{* * *}$ & $0.219^{* * *}$ & $0.188^{* * *}$ & $0.148^{* * *}$ & $0.186^{* * *}$ & $0.136^{* * *}$ & $0.232^{* * *}$ & $0.190^{* * *}$ & $0.230^{* * *}$ & $0.168^{* * *}$ & $0.123^{* * *}$ & $0.129^{* * *}$ \\
\hline secundaria incompleta & $\begin{array}{l}(0.0244) \\
0.267^{* * *}\end{array}$ & $\begin{array}{l}(0.0205) \\
0.367^{* * *}\end{array}$ & $\begin{array}{l}(0.0240) \\
0.298 * * *\end{array}$ & $\begin{array}{l}(0.0254) \\
0.236 * * *\end{array}$ & $\begin{array}{l}(0.0418) \\
0.282 * * *\end{array}$ & $\begin{array}{l}(0.0369) \\
0.289 * * *\end{array}$ & $\begin{array}{l}(0.0426) \\
0.385 * * *\end{array}$ & $\begin{array}{l}(0.0422) \\
0.262^{* * * *}\end{array}$ & $\begin{array}{l}(0.0437) \\
0.292 * * *\end{array}$ & $\begin{array}{l}(0.0348) \\
0.243 * * *\end{array}$ & $\begin{array}{l}(0.0389) \\
0.239 * * *\end{array}$ & $\begin{array}{l}(0.0399) \\
0.160^{* * * *}\end{array}$ \\
\hline & $(0.0258)$ & $(0.0216)$ & $(0.0257)$ & $(0.0269)$ & $(0.0452)$ & $(0.0392)$ & $(0.0444)$ & $(0.0440)$ & $(0.0416)$ & $(0.0330)$ & $(0.0368)$ & $(0.0383)$ \\
\hline secundaria completa & $0.506^{* * *}$ & $0.575^{* * *}$ & $0.517^{* * *}$ & $0.415^{* * *}$ & $0.483^{* * *}$ & $0.566^{* * *}$ & $0.618^{* * *}$ & $0.454^{* * *}$ & $0.469^{* * *}$ & $0.474^{* * *}$ & $0.445^{* * *}$ & $0.351^{* * *}$ \\
\hline & $(0.0261)$ & $(0.0217)$ & $(0.0264)$ & $(0.0273)$ & $(0.0488)$ & $(0.0394)$ & $(0.0439)$ & $(0.0441)$ & $(0.0431)$ & $(0.0339)$ & 85) & $(0.0395)$ \\
\hline universitario incompleto & $0.728^{* * *}$ & $0.792^{* * *}$ & $0.682^{* * *}$ & $0.592 * * *$ & $0.724^{* * *}$ & $0.789 * * *$ & $0.738^{* * *}$ & $0.628 * * *$ & $0.637^{* * *}$ & $0.640^{* * *}$ & $0.584^{* * *}$ & $0.547^{* * *}$ \\
\hline & $(0.0280)$ & $(0.0233)$ & $(0.0258)$ & $(0.0271)$ & $(0.0615)$ & $(0.0476)$ & $(0.0499)$ & $(0.0503)$ & $(0.0423)$ & $(0.0331)$ & $(0.0366)$ & $(0.0368)$ \\
\hline universitario completo & $1.107^{* * *}$ & $1.160^{* * *}$ & $1.016^{* * *}$ & $0.847^{* * *}$ & $1.091^{* * *}$ & $1.175^{* * *}$ & 1.18 & $0.938^{* * *}$ & $1.024^{* * *}$ & $0.993^{* * *}$ & $0.911^{* * *}$ & $0.779 * * *$ \\
\hline & $(0.0294)$ & $(0.0235)$ & $(0.0303)$ & $(0.0302)$ & $(0.114)$ & $(0.0575)$ & $(0.0585)$ & $(0.0585)$ & $(0.0480)$ & $(0.0379)$ & $(0.0422)$ & $(0.0432)$ \\
\hline hombre & $0.174^{* * *}$ & $0.197^{* * *}$ & $0.207^{* * *}$ & $0.126^{* * *}$ & $-0.196^{*}$ & -0.0143 & 0.0131 & -0.0664 & $0.0573^{* * *}$ & $0.177^{* * *}$ & $0.164^{* * *}$ & $0.108^{* * *}$ \\
\hline & $(0.0280)$ & $(0.0290)$ & $(0.0280)$ & $(0.0254)$ & $(0.117)$ & $(0.0655)$ & $(0.0538)$ & $(0.0525)$ & $(0.0194)$ & $(0.0164)$ & $(0.0180)$ & $(0.0171)$ \\
\hline edad & $0.0637^{* * *}$ & $0.0208^{* * *}$ & $0.0316^{* * *}$ & $0.0134^{* *}$ & 0.0244 & $0.0243^{* *}$ & & 0.01 & 0.073 & $0.0585 * * *$ & $0.0440^{* * *}$ & $0.0412 * * *$ \\
\hline & $(0.00828)$ & $(0.00685)$ & $(0.00704)$ & $(0.00608)$ & $(0.0161)$ & $(0.0103)$ & $(0.00896)$ & $(0.00859)$ & $(0.00855)$ & $(0.00596)$ & $(0.00649)$ & $(0.00617)$ \\
\hline edad2 & $-0.000660^{* * *}$ & $-0.000143^{*}$ & $-0.000317^{* * *}$ & $-7.94 e-05$ & -0.000165 & -0.000161 & $3.00 \mathrm{e}-05$ & $-3.04 \mathrm{e}-05$ & $-0.000826^{* * *}$ & $-0.000613^{* * *}$ & $* 0.000443^{* * *}$ & $-0.000413^{* * *}$ \\
\hline & $(0.000106)$ & $(8.65 \mathrm{e}-05)$ & $(8.79 e-05)$ & $(7.53 \mathrm{e}-05)$ & $(0.000210)$ & $(0.000127)$ & $(0.000109)$ & $(0.000103)$ & $(0.000113)$ & $(7.91 \mathrm{e}-05)$ & $(8.48 \mathrm{e}-05)$ & $(7.97 \mathrm{e}-05)$ \\
\hline menor18 & & & & & & & & & -0.1 & -0.1 & **** & 0.0 \\
\hline & & & & & & & & & $(0.0$ & & $(0.0526)$ & $(0.0543)$ \\
\hline pampeana & -0.15 & -0.1 & -0. & -0. & -0.1 & -0 & & -0.0 & -0.18 & & & -0.07 \\
\hline & $(0.0184)$ & $(0.0151)$ & $(0.0151)$ & $(0.0130)$ & $(0.0279)$ & & & & & & & \\
\hline Cuyo & $-0.313^{* * *}$ & $-0.253^{* * *}$ & $-0.250^{* * *}$ & $-0.156^{* * *}$ & $-0.306^{* * *}$ & $-0.274^{* * *}$ & $-0.281^{* * *}$ & $-0.162^{* * *}$ & $-0.344^{* * *}$ & $-0.272^{* * *}$ & $-0.330^{* * *}$ & $-0.271 * * *$ \\
\hline & $(0.0235)$ & $(0.0198)$ & $(0.01$ & $(0.0173)$ & $(0.0373)$ & $(0.0318)$ & & $(0.02)$ & $(0.0$ & 37) & & $(0.0207)$ \\
\hline NOA & $-0.382 * * *$ & $-0.390^{* * *}$ & $-0.321 * * *$ & $-0.262^{* * * *}$ & $-0.418 * * *$ & $-0.346 * * *$ & $-0.325 * * *$ & $-0.279 * * *$ & $-0.453 * * *$ & $-0.502 * * *$ & $-0.451 * * *$ & $-0.416^{* * * *}$ \\
\hline & $(0.0209)$ & $(0.0172)$ & $(0.0168)$ & $(0.0145)$ & $(0.0329)$ & $(0.0281)$ & $(0.0266)$ & $(0.0224)$ & $(0.0247)$ & $(0.0$ & $(0.0$ & $(0.0$ \\
\hline Patagonia & $0.173^{* * *}$ & $0.403^{* * *}$ & $0.390^{* * *}$ & $0.439 * * *$ & $0.194^{* * *}$ & $0.363^{* * *}$ & $0.343^{* * *}$ & $0.417^{* * *}$ & $0.157^{* * *}$ & & $0.272^{* * *}$ & $0.347^{* * *}$ \\
\hline & $(0.0262)$ & $(0.0190)$ & $(0.0185)$ & $(0.0172)$ & $(0.0399)$ & $(0.0309)$ & $(0.0294)$ & $(0.0266)$ & $(0.0386)$ & $(0.0250)$ & & $(0.0249)$ \\
\hline NEA & $-0.490^{* * *}$ & $-0.486^{* * *}$ & $-0.410^{* * *}$ & $-0.328 * * *$ & $-0.454^{* * * *}$ & $-0.489 * * *$ & $-0.464^{* * *}$ & $-0.317^{* * *}$ & $-0.535 * * *$ & $-0.577^{* * * *}$ & $-0.500^{* * * *}$ & $-0.427^{* * *}$ \\
\hline & $(0.0251)$ & $(0.0193)$ & $(0.0194)$ & $(0.0181)$ & $(0.0367)$ & $(0.0315)$ & $(0.0297)$ & $(0.0285)$ & $(0.0337)$ & & $(0.0250)$ & $(0.0234)$ \\
\hline onstante & $1.441 * * *$ & $2.526 * * *$ & $2.457^{* * *}$ & $2.985 * * *$ & $2.448 * * *$ & $2.593^{* * * *}$ & $3.025 * * *$ & $3.114^{* * *}$ & $1.258 * * *$ & $1.756^{* * *}$ & $2.208 * * *$ & $2.431 * * *$ \\
\hline & $(0.197)$ & $(0.171)$ & $(0.182)$ & $(0,162)$ & $(0.501)$ & $(0.291)$ & $(0,246)$ & $(0.247)$ & & & & ) \\
\hline Ecuación de & & & & & & & & & & & & \\
\hline primaria completa & 0.00762 & 0.0316 & $0.149^{* * * *}$ & *** & 0.0233 & 0.0 & 0.06 & 0.12 & 0.32 & & 0.39 & $0.602^{* * *}$ \\
\hline & & & & & $(0.0$ & & & & & & & \\
\hline secundaria incompleta & $0.0694^{*}$ & $0.0630^{*}$ & $0.256^{* * *}$ & $0.330^{* * *}$ & 0.05 & :* & *** & *** & ** & & & ** \\
\hline & $(0.0382)$ & $(0.03$ & $(0.03$ & $(0.04$ & $(0.0$ & $(0.0$ & & $(0.0$ & & & & \\
\hline secunda & $0.161^{* * *}$ & $0.166^{* * *}$ & $0.357^{* * *}$ & $0.409^{* * *}$ & $0.143^{* * *}$ & $0.184^{* * *}$ & $0.266^{* * *}$ & $0.351^{* * *}$ & 0.35 & **** & $0.619^{* * *}$ & $0.800^{* * *}$ \\
\hline & $(0.0383)$ & $(0.0343)$ & $(0.0369)$ & $(0.0393)$ & $(0.0442)$ & $(0.0$ & & $(0.05$ & & & & \\
\hline universitario incompleto & $0.172^{* * *}$ & $0.0989 * *$ & $0.293^{* * *}$ & $0.398^{* * *}$ & $0.246^{* * *}$ & $0.337^{* * *}$ & & 0.52 & 0.38 & & & 0.84 \\
\hline & $(0.0463)$ & $(0.0411)$ & $(0.0442)$ & & $(0.0552)$ & & & & & & & \\
\hline universitario completo & $0.392^{* * *}$ & $0.271^{* * *}$ & $0.578^{* * *}$ & $0.602^{* * *}$ & $0.804^{* * *}$ & $0.700^{* * *}$ & $0.869 * * *$ & $924^{* * *}$ & **** & **** & $0.819^{* * *}$ & $1.016^{* * *}$ \\
\hline & $(0.04$ & $(0.03$ & & & & & & & & & & \\
\hline hombre & $0.506^{* * *}$ & $0.723^{* * *}$ & $0.763^{* * *}$ & $0.778^{* * * *}$ & $0.926^{* * *}$ & $1.120^{* * *}$ & $1.284^{* * *}$ & $1.278^{* * *}$ & $0.276^{* * *}$ & 0.4 & **** & $0.531^{* * * *}$ \\
\hline & $(0.0279)$ & $(0.0226)$ & $(0.0219)$ & $(0.02$ & $(0.04$ & $(0.0$ & & $(0.03$ & & & & \\
\hline edad & $0.147^{* * *}$ & $0.164^{* * *}$ & $0.178^{* * *}$ & $0.174^{* * *}$ & $0.120^{* * *}$ & $0.166^{* * *}$ & & $0.179^{* * *}$ & $0.175^{* * *}$ & & $0.188^{* * *}$ & \\
\hline & $(0.00644)$ & $(0.00573)$ & $(0.00577)$ & $(0.00576)$ & $(0.00737)$ & $(0.00676)$ & $(0.00711)$ & $(0.00714)$ & $(0.00618)$ & & $(0.00551)$ & \\
\hline edad2 & $-0.00198 * * *$ & $-0.00216^{* * *}$ & $-0.00230^{* * *}$ & $-0.00225^{* * *}$ & $-0.00159 * * *$ & $-0.00211 * * *$ & $-0.00232 * * *$ & $-0.00224^{* * * *}$ & $-0.00225^{* * * *}$ & $-0.00228^{* * * *}$ & $-0.00239 * * *$ & -0.002 \\
\hline & $(7.40 \mathrm{e}-05)$ & $(6.57 \mathrm{e}-05)$ & $(6.61 \mathrm{e}-05)$ & $(6.51 \mathrm{e}-05)$ & $(8.95 \mathrm{e}-05)$ & $(8.13 \mathrm{e}-05)$ & & $(8.38 \mathrm{e}-05)$ & $(8.37$ & & $(7.39 \mathrm{e}-05)$ & \\
\hline casado & $0.0930^{* * * *}$ & $0.0483^{* *}$ & -0.00690 & $0.0495^{* *}$ & & & & & 0.00 & $-0.0510^{* *}$ & -0.0 & -0. \\
\hline & & $(0.0232)$ & & $(0.02$ & & & & & & & & \\
\hline numero hijos & $0.0236 * * *$ & $-0.0274^{* * * *}$ & $-0.0394^{* * * *}$ & $-0.0511^{* * * *}$ & -0.043 & -0.0 & & & & & & \\
\hline & $(0.00824)$ & $(0.00731)$ & & & & & & & & & & \\
\hline menor18 & & & & & & & & & -0.52 & & & \\
\hline & & & & & & & & & & & & \\
\hline asiste & $-0.696^{* * *}$ & $-0.621^{* * *}$ & $-0.553^{* * * *}$ & $-0.576^{* * *}$ & -0.0502 & -0.0588 & $-0.0998^{*}$ & $-0.101^{*}$ & -0.71 & $-0.826^{* * *}$ & $-0.789 * * *$ & $* * *$ \\
\hline & & & & & $(0.0635)$ & & & & & & & \\
\hline jefe ocupado & & & & & $-0.0660^{* *}$ & $-0.0949 * * *$ & 0.0237 & -0.00105 & $0.0704^{* * *}$ & $0.0499 * * *$ & $0.0677^{* * *}$ & $0.0509 * * *$ \\
\hline & & & & & & & & & & & & \\
\hline conyuge ocupado & & & & & & & & & -0.0241 & 0.0 & -0.0 & -0.0 \\
\hline & & & & & & & & & & & & \\
\hline pampeana & & $-0.0830^{* * * *}$ & & & & & & & -0.09 & $-0.111^{* * *}$ & $-0.163^{* * * *}$ & -0.0239 \\
\hline & & & & & & & & & & & & \\
\hline Cuyo & 0.0373 & -0.0230 & -0.00206 & $0.0710^{* *}$ & 0.0233 & 0.0399 & -0.0566 & 0.0301 & $-0.0989 * * *$ & $-0.132^{* * *}$ & $-0.203^{* * *}$ & -0.00312 \\
\hline & & & & & & & & & & & & \\
\hline NOA & $-0.157^{* * *}$ & $-0.158^{* * * *}$ & $-0.115^{* * *}$ & $-0.0665 * *$ & $0.0803^{* *}$ & $-0.0787^{* *}$ & -0.0384 & 0.0326 & -0.11 & $-0.239 * * *$ & $-0.258^{* * * *}$ & -0.08 \\
\hline & & & $(0.0306)$ & & $(0.0360)$ & & & & & & $(0.0284)$ & $(0.0257)$ \\
\hline Patagonia & $-0.120^{* * *}$ & $-0.0991 * * *$ & -0.0330 & -0.0518 & 0.0252 & -0.0354 & 0.0394 & 0.0123 & $-0.148 * * *$ & $-0.127^{* * *}$ & $-0.142^{* * * *}$ & $-0.0850^{* * *}$ \\
\hline & & & & & & & & & & & & \\
\hline NEA & $-0.244^{* * *}$ & $-0.162^{* * *}$ & $-0.189^{* * *}$ & $-0.180^{* * *}$ & 0.0213 & $-0.0841^{* *}$ & -0.0209 & $-0.134^{* * *}$ & $-0.306^{* * *}$ & $-0.398 * * *$ & $-0.358^{* * * *}$ & $-0.305^{* * *}$ \\
\hline & & & & & & & & & & & & \\
\hline constante & $-2.122 * * *$ & $-2.550^{* * *}$ & $-3.015^{* * * *}$ & $-3.060 * * *$ & $-2.336^{* * * *}$ & $-3.205 * * *$ & $-3.652^{* * * *}$ & $-3.746^{* * *}$ & $-3.228^{* * * *}$ & $-3.239 * * *$ & $-3.605^{* * * *}$ & $-4.265 * * *$ \\
\hline & $(0.137)$ & $(0.123)$ & $(0.125)$ & $(0.127)$ & $(0.146)$ & $(0$. & $(0.148)$ & $(0.152)$ & $(0.114)$ & $(0.0993)$ & $(0.106)$ & $(0.106)$ \\
\hline obs & 20,860 & 27,209 & 26,056 & 26,990 & 14,546 & 18,388 & 16,903 & 17,356 & 24,126 & 31,491 & 28,252 & 29,914 \\
\hline $\mathrm{Chi}_{2}$ & 43 & & & & & & & 25 & 19 & 39 & 274 & 2975 \\
\hline ho & $0.2>2-3$ & -0.0860 & 1 & -0 . & -0 . & -0.272 & -0.200 & -0.255 & 0.194 & 0.145 & 0.104 & 0.0131 \\
\hline Sigma & 0.76 & 0.6 & & & & & 0.688 & 0.650 & 0.739 & 668 & 0.653 & 0.614 \\
\hline Lambda & 0.203 & -0.0588 & 0.113 & -0.101 & -0.168 & -0.194 & -0.141 & -0.166 & 0.143 & 0.0969 & 0.0677 & 0.00805 \\
\hline
\end{tabular}

*** $p<0.01, * * p<0.05 * * 0<0.1$

Nota: Estimación de Heckman en dos etapas. Trabajadores entre 15 y 65 años con respuestas válidas. Fuente: Elaboración propia en base a datos de la EPH. 
Tabla A.2: Ecuación de horas trabajadas.

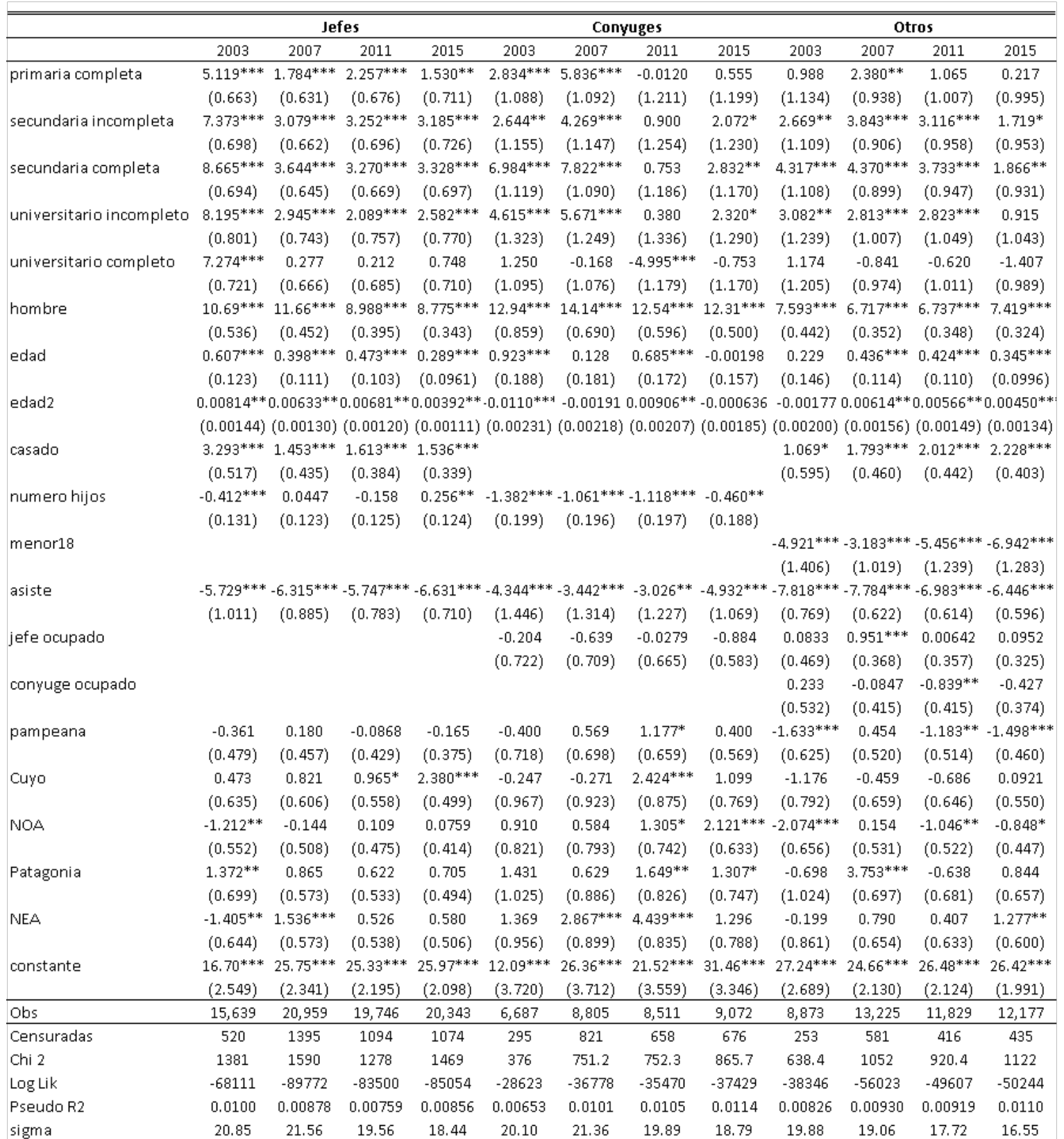

Nota: Estimación de Tobit de las horas trabajadas. Trabajadores entre 15 y 65 años con respuestas válidas.

Fuente: Elaboración propia en base a datos de la EPH. 